\title{
Weertman regelation, multiple refreezing events and the isotopic evolution of the basal ice layer
}

\author{
BRYN HUbBard AND Martin SHARP \\ Department of Geography, University of Cambridge, Cambridge CB2 3EN, England
}

\begin{abstract}
A simple model is developed to simulate the isotopic fractionation which accompanies Weertman regelation at the bed of temperate-based glaciers. The fractionation equations of Jouzel and Souchez (1982) are applied to multiple refreezing events over measured glacier-bed profiles, and mass balance is maintained as the basal ice and meltwater produced at one bedrock hummock enter the next. Simulation results indicate that undeformed regelation ice layers are on the order of millimetres to centimetres thick, often being completely melted at the stoss face of certain hummocks and exceptionally reaching a thickness in excess of $10 \mathrm{~cm}$. Neither the internal morphology nor the isotopic composition of these layers is constant, but both vary down-glacier in accordance with bedrock configuration. A glacier-wide fractionation process is identified whereby heavy isotopes are preferentially removed from the basal meltwater film and incorporated into the basal ice. This process might go some way to explaining the anomalously "light" isotopic composition measured in base-flow waters leaving some glaciers. Vertical isotope profiles through undeformed basal ice layers are reconstructed and show that significant isotopic excursions can occur at a scale of millimeteres, while the range of isotopic compositions within such multi-layered regelation ice is greater than that which would occur in ice produced by a single refreezing event. In circumstances where the regelation system is disrupted by removal of film waters into a network of linked cavities, it is found that the remaining basal ice may be significantly enriched in heavy isotopes relative to the composition of the initial mass inputs to the system. Heavy isotope enrichment of this magnitude and consideration of the thickness of the basal ice layers concerned may explain the absence of recorded basal ice samples heavy enough to have been formed in equilibrium with subglacial precipitates sampled at one of the sites (Glacier de Tsanfleuron) and reported in an earlier paper.
\end{abstract}

\section{INTRODUCTION}

The formation of basal ice by regelation, with its accompanying isotopic fractionation, is repeated many times as a temperate-based glacier slides over its bed. Conservation of mass dictates that such multiple refreezing phases are closely interdependent, with both ice and water outputs from up-glacier locations representing inputs to melting-refreezing events down-glacier. In the present analysis, we attempt to track the evolution in isotopic composition of the basal ice layer and the net basal meltwater film as the glacier slips over its bed by pressure-melting and refreezing.

Weertman regelation, which contributes to basal sliding of temperate glaciers, involves the melting and refreezing of ice at the pressure-melting point around small bedrock hummocks (Weertman, 1957, 1964). Pressure on ice at the basal interface increases upstream of bed protuberances and its melting point is correspondingly lowered. As a result, the ice melts and the meltwater flows as a film along the pressure gradient to the lee side of the bump where the pressure is reduced, the melting point raised and the film refrozen. This releases latent heat of fusion which is conducted back through the rock to the stoss face where it is utilized in further melting, a transfer which is considered to limit the length of bumps around which regelation occurs to $1 \mathrm{~m}$ or so (Kamb, 1970). The operation of Weertman regelation is most effective over smaller bumps, such that there is a "transition wavelength" above which plastic deformation in the basal ice becomes a more important flow process than regelation. According to the theoretical treatments of Nye (1969, 1970) and Kamb (1970), this represents the "controlling obstacle size" to basal slip and is of the order of $50 \mathrm{~cm}$. Support for such a regelation process has come from both theoretical modelling and direct observation at the glacier bed (Kamb and LaChapelle, 1964; Hallet and others, 1978), although it has eluded realistic laboratory simulation, principally due to the requirement for a closed thermal system which is maintained at the pressure-melting point (Goodman and others, 1979; Hooke and Iverson, 1985).

One significant consequence of Weertman regelation is that it results in the formation of a thin basal ice layer, often composed of many closely spaced laminae of clear, refrozen ice, the upper surface of each being defined by a thin debris plane (Fig. 1). Although such "laminated ice" has been observed widely in the field, it has also been suggested that, in certain circumstances, regelation may be responsible for the formation of a very different basal 


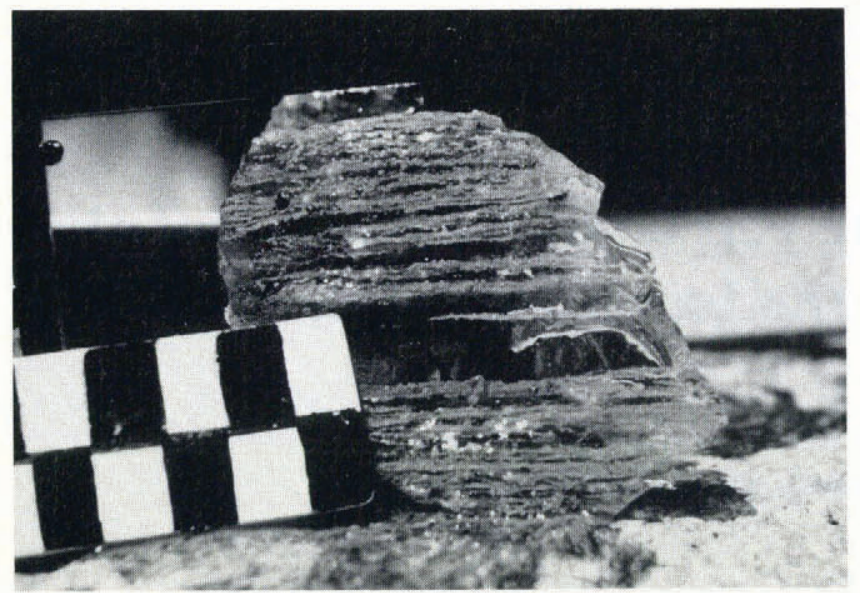

Fig. 1. A laminated, regelation basal ice layer recovered from the bed of Glacier de Ferpècle, Switzerland.

ice facies, termed "clotted ice". This facies has been identified at Russell Glacier, Greenland, by Knight (1987), Sugden and others (1987a) and Souchez and others (1988a), and consists of up to tens of metres of generally bubble-free ice containing elongated debris clots, composed principally of silt-sized particles. The evidence for formation of this facies by Weertman regelation is, however, not strong and Koerner (1989) argued that clotted ice was formed as superimposed ice charged with wind-blown debris during the last interglacial. Even if this facies is formed by regelation in the temperate interior of large ice masses, it seems likely to have undergone significant tectonic deformation and thickening and, while its origin does present a challenging problem, the term "regelation ice" is here reserved for the more widespread laminated ice facies. The thickness of undeformed regelation ice layers has been determined theoretically to be of the order of millimetres to a few centimetres (Nye, 1970) which is in general accordance with the few field observations which have been reported (e.g. Kamb and LaChapelle, 1964). The chemical composition of the ice may reflect the effects of solute rejection during refreezing. Where calcite precipitation occurs in the lee of bedrock bumps as a result of such rejection, the calcium content of the ice may be determined theoretically from phase relations at the eutectic point in association with a realistic partition coefficient between the water and the ice formed from it (Hallet, 1976; Hallet and others, 1978).

More recently, refrozen basal ice has been identified and analysed in terms of the isotopic composition of its two principal constituent elements (oxygen, analysed in terms of ${ }^{16} \mathrm{O}$ and ${ }^{18} \mathrm{O}$, and hydrogen, analysed in terms of ${ }^{1} \mathrm{H}$ and ${ }^{2} \mathrm{H}$ (deuterium)). Isotopic fractionation occurs during the freezing of water as a result of the different physical behaviour of the isotopes, and particularly as a result of the tendency of heavier nuclei to form stronger bonds. The mass balance of this preferential incorporation of heavy isotopes has been modelled by Jouzel and Souchez (1982). The mean isotopic content of the ice in any decimetric frozen fraction of a finite reservoir (denoted as " $K$ " and defined as $N_{\mathrm{g}} / N_{\mathrm{o}}$ where $N_{\mathrm{s}}$ is the number of moles in the solid fraction at any given time and $N_{0}$ is the total number of moles in the initial reservoir) is given by:

$$
\delta_{\mathrm{s}}=10\left(1000+\delta_{\mathrm{o}}\right)\left[(1.1-K)^{f}-(1-K)^{f}\right]-1000 \% \text {. }
$$

Here " $\delta_{\mathrm{s}}$ " is the mean isotopic composition of the solid phase, " $\delta_{0}$ " is the isotopic composition of the initial liquid and " $f$ " is the equilibrium "fractionation factor" between ice and water, defined by:

$$
f=R_{\text {ice }} / R_{\text {water }} .
$$

$R_{\text {ice }}$ and $R_{\text {water }}$ are the ratios of heavy to light isotopes in the ice and the water reservoir from which it has frozen. The relationship holds equally for deuterium and ${ }^{18} \mathrm{O}$, and the respective fractionation factors are 1.0208 (Arnason, 1969) and 1.003 (O'Neil, 1968). Upon slow, equilibrium refreezing, therefore, the ice initially formed may be enriched in ${ }^{18} \mathrm{O}$ relative to ${ }^{16} \mathrm{O}$ by up to $3 \%$ (expressed relative to Standard Mean Ocean Water (SMOW)) (O'Neil, 1968), while ice formed subsequently is progressively depleted in this isotope until, after about two-thirds of the initial reservoir has been frozen, it becomes isotopically lighter than the source or "initial liquid" (Fig. 2). Significantly, the different fractionation factors result in a predictable change in the slope of the straight-line plot of $\delta^{18} \mathrm{O}$ (plotted as the abscissa) against $\delta \mathrm{D}$ (plotted as the ordinate) in ice which has been refrozen. Whereas the universal "precipitation slope" for unaltered waters is described by

$$
\delta \mathrm{D}=8 \delta^{18} \mathrm{O}+10
$$

(3) - (Craig and others, 1963)

the slope, upon refreezing, becomes

$$
S=\frac{(\alpha-1) \times\left(1000+\delta_{0} \mathrm{D}\right)}{(\beta-1) \times\left(1000+\delta_{0}^{18} \mathrm{O}\right)}
$$

(4) - (Jouzel and Souchez, 1982)

where $\alpha$ and $\beta$ are the equilibrium fractionation coefficients for deuterium and oxygen, respectively. For

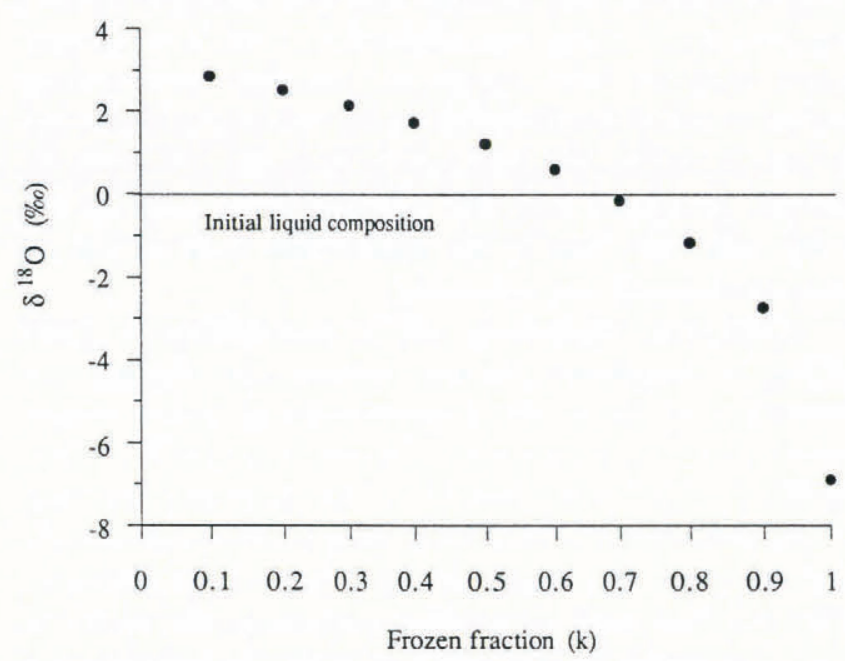

Fig. 2. Plot of $\delta^{18} O$ in ten successive frozen fractions formed from SMOW (initial $\delta^{18} \mathrm{O}=0$ ) after Jouzel and Souchez (1982). 
most waters in the glacial environment this results in a "refreezing slope" in the range of 4.5-6.9, and the relationship has been used extensively in the field as an aid both to the identification of refrozen ice facies and in the more detailed analysis of their provenance (e.g. Souchez and Jouzel, 1984; Souchez and de Groote, 1985; Knight, 1987; Sugden and others, 1987a, b; Gordon and others, 1988).

\section{THE ISOTOPIC SIGNAL IN REGELATION ICE}

There is no consensus as to a diagnostic isotopic "fingerprint" for regelation ice. It is accepted that such ice has been refrozen at the basal interface, but its isotopic composition is complicated by a number of factors. First, and critically, is the relationship between the size of the ice sample analysed and the scale of the individual refreezing events concerned. For slope differentiation to be possible on a co-isotopic plot, samples must consist of ice recovered from within a layer formed by a single refreezing event because mass is conserved over entire events. However, as a glacier slides over its bed by regelation, the basal ice layer which forms in the lee of a bed protuberance is at least partially destroyed by melting at the stoss surface of the next bump encountered downstream. This bump in turn results in the formation of a second refrozen ice layer which will underlie the first one if it was not completely destroyed, and so on, resulting in the familiar laminated ice facies depicted in Figure 1. Thus, although the net basal ice layer is essentially limited to an apparently stable thickness of a few centimetres, in reality it is continuously evolving downstream in accordance with the bed configuration over which it flows, both in terms of its internal morphology and its isotopic composition. If, as has been determined theoretically, the regelation process operates effectively only around bumps less than $1 \mathrm{~m}$ in length, then it is likely that the amplitude of each bump and therefore of individual refrozen layers, is of the order of millimetres to centimetres. If the net basal ice layer is then sampled with a cyclindrical sampler of internal diameter of $2 \mathrm{~cm}$ or so, it follows that what is actually being collected may not be ice from within a single refrozen layer but from several individual partial layers. Souchez and others (1988a) have reported this effect in their analysis of the isotopic character of clotted ice at Russell Glacier, described above. These authors concluded that, although this ice facies was believed on stratigraphical and sedimentological grounds to have been formed by regelation, it was not characterized by a refreezing slope because the scale of sampling may have been too coarse and isotopic mass had therefore been conserved. It should be noted, however, that it is only when a sample includes completely refrozen layers formed in a closed system that it remains on the precipitation slope: a sample will still plot on the freezing slope if the individual layers included within it do not represent complete refreezing events.

An associated problem arises from the dependence of the freezing slope on the isotopic composition of the initial liquid from which it is frozen (in accordance with the relationship described in Equation (4)). Whilst a unique freezing slope is only apparent in co-isotopic plots of ice samples formed from similar initial liquids, as we have seen, samples of laminated ice may include a number of individual layers, each probably formed from a different initial liquid. The reason for this is that regelation ice forms from a thin basal meltwater film the thickness of which may be dictated by bedrock morphology such that it is incremented at bumps where there is an excess of melting over refreezing (stoss-face amplitude greater than lee-face amplitude) and thins where the reverse is true. Continuous overturning in the film makes it probable that its isotopic composition fluctuates or evolves in a down-glacier direction in accordance with the isotopic distribution through the basal ice layer being melted and fractionation effects in the film as it refreezes. In addition, bedrock bumps may protrude through the basal ice layer at certain locations and result in the melting of overlying glacier ice, which may be of a different isotopic composition from both the basal ice and the basal meltwater. These effects imply that the isotopic composition of the basal ice layer and the basal meltwater film are not constant, but that they evolve down-glacier in an interdependent manner. Furthermore, Weertman regelation does not occur in isolation at the bed of a glacier. At some locations, the system may connnect with a linked cavity-orifice network (Walder, 1986) where both the basal ice layer and the basal film may be partially or completely lost by melting and through drainage into this network, respectively.

While there is neither a constant internal morphological composition nor an initial liquid unique to multiple layers of regelation ice, the actual variability involved has not been quantified and the extent of scatter of samples on co-isotopic plots attributable to these effects has not been determined. There is a requirement, therefore, not only to track these characteristics quantitatively as the basal ice layer undergoes multiple melting-refreezing events, but also to link their evolution to actual bed configurations as measured in the field. To these ends, basal ice evolution has been modelled through applying the analysis of Jouzel and Souchez (1982) to regelation over measured hard glacier-bed profiles.

\section{THE MODEL}

A simple model has been developed in which the glacier bed is characterized as a series of bedrock hummocks over which the thickness of ice which melts and forms is equal to the amplitude of the stoss and lee faces of the individual bumps, respectively. A net basal-melting term is incorporated into the model, which has the effect of melting slightly more ice at the stoss face of each bump than would otherwise occur. Following Paterson (1981), net basal melting in temperate glaciers results predominantly from geothermal heating and basal friction, each of which typically produces c. $6 \mathrm{~mm}$ of melt $\mathrm{a}^{-1}$ at a sliding rate of $20 \mathrm{~m} \mathrm{a}^{-1}$. Net basal melting of $12 \mathrm{mma}^{-1}$ is therefore incorporated into the analysis and scaled over the profiles assuming a sliding rate of $20 \mathrm{~m} \mathrm{a}^{-1}$ (i.e. $0.6 \mathrm{~mm}$ of vertical melt per horizontal metre traversed). Mass is conserved such that the output from one bump is carried over as input to the next. Thus, at a bump where more ice is melted than refrozen, the net basal water film is 
incremented by the difference and vice versa. Where the crest of any bump protrudes above the upper surface of the influent basal ice layer, the corresponding amount of glacier ice is melted and, where the crest of the bump is lower than the upper surface of the basal ice layer, then the excess survives melting to overlie the new regelation ice formed in the lee of that bump.

Flow-parallel profiles of deglaciated, hard glacier beds were measured, at a $5 \mathrm{~cm}$ point spacing, with a theodolite and electro-optical distance meter at a relict valley glacier in Snowdonia, North Wales (Sharp and others, 1989a) and at Glacier de Tsanfleuron, Switzerland, and with a beam and stylus profilometer, at a $0.5 \mathrm{~cm}$ point spacing, on two bedrock types at Midtdalsbreen, Norway (Willis and others, 1990). Bedrock lithologies were ignimbrite tuff, Cretaceous limestone, phyllite and granite, respectively. The Norwegian profiles were resampled at a spacing of $5 \mathrm{~cm}$ for consistency. In order to remove the influence of plastic deformation of the ice from the model, larger-scale roughness features of length greater than $50 \mathrm{~cm}$ were removed by smoothing the profiles with a fivepoint running mean (i.e. over $25 \mathrm{~cm}$ ), subtracting the vertical coordinates of the smoothed curve from the actual profiles and plotting the residuals. The $50 \mathrm{~cm}$ cut-off point was chosen for computational simplicity and lies within the length range of $0.25-1 \mathrm{~m}$, below which regelation is the principal sliding mechanism and above which it is dominated by the effects of enhanced creep (Kamb, 1970). The resulting long profiles thus represent the glacier beds as "seen" by the process of regelation in the model. In order to characterize the beds by those components important to regelation, each bump was represented by straight-line stoss-and-lee faces meeting at the bump crest. The base of the first bump in each profile is denoted by horizontal distance and elevation $(0.000 \mathrm{~m}$; $0.000 \mathrm{~m}$ ) and the rest of the beds by the coordinates of individual bump crests and intervening troughs. Where smaller bumps occur on the faces of larger bumps, they are removed in the model and re-introduced end-to-end. While this procedure involves departing from the actual bed profiles, it closely approximates the roughness characteristics of the original beds and greatly simplifies computation. The characteristics of the reconstructed profiles are described in Table 1.

A number of morphological parameters are calculated which relate to the thickness of the basal ice layer and the basal meltwater film as they evolve along the profiles. A schematic representation of these model components for the first three bumps of the profile measured at Glacier de Tsanfleuron is given in Figure 3.

Local melt $(\mathrm{m})$ - given by the vertical relief of the stoss face of each bump plus a net basal melting term as described above.

Net basal melt-film thickness at bump crests (m) - given by the melt-film thickness inherited from the trough of the previous hummock plus local melt. It is assumed that longitudinal gradient in meltwater potential is controlled by the ice-surface gradient. Meltwater generated at the stoss face cannot, therefore, flow back up-glacier into the preceding trough.

Local refrozen ice layer $(\mathrm{m})$ - given by the vertical relief of the lee face of each bump or the quantity of water in the meltwater film at the crest of the bump if this is less.

Table 1. Physical characteristics of the four reconstructed bedrock profiles

$\begin{array}{lccc}\text { Glacier } & \text { Profile length } & \begin{array}{c}\text { Number of } \\ \text { individual bumps }\end{array} & \lambda\end{array} \quad \frac{a^{*}}{\lambda}$

$\mathrm{m}$

\begin{tabular}{|c|c|c|c|c|c|}
\hline Tsanfleuron & 22.48 & 103 & $\begin{array}{l}\text { Mean } \\
\text { Minimum } \\
\text { Maximum }\end{array}$ & $\begin{array}{l}0.218 \\
0.083 \\
0.500\end{array}$ & $\begin{array}{l}0.028 \\
0.002 \\
0.084\end{array}$ \\
\hline $\begin{array}{l}\text { Midtdalsbreen } \\
\text { (phyllite) }\end{array}$ & 19.91 & 91 & $\begin{array}{l}\text { Mean } \\
\text { Minimum } \\
\text { Maximum }\end{array}$ & $\begin{array}{l}0.219 \\
0.079 \\
0.472\end{array}$ & $\begin{array}{l}0.140 \\
0.006 \\
0.921\end{array}$ \\
\hline $\begin{array}{l}\text { Midtdalsbreen } \\
\text { (granite) }\end{array}$ & 19.01 & 106 & $\begin{array}{l}\text { Mean } \\
\text { Minimum } \\
\text { Maximum }\end{array}$ & $\begin{array}{l}0.179 \\
0.075 \\
0.485\end{array}$ & $\begin{array}{l}0.031 \\
0.004 \\
0.273\end{array}$ \\
\hline North Wales & 21.72 & 99 & $\begin{array}{l}\text { Mean } \\
\text { Minimum } \\
\text { Maximum }\end{array}$ & $\begin{array}{l}0.219 \\
0.044 \\
0.491\end{array}$ & $\begin{array}{l}0.044 \\
0.007 \\
0.140\end{array}$ \\
\hline
\end{tabular}

\footnotetext{
" "a" denotes hummock amplitude.
} 


\begin{tabular}{|c|c|c|c|c|c|c|c|}
\hline Distance $(\mathrm{cm})$ & 0 & 6.5 & 13.0 & & 22.7 & 32.5 & 40.4 \\
\hline Sloss (mm) & 7.8 & & & 12.7 & & & \\
\hline Melt (mm) & $\begin{array}{l}7.9 \\
\ldots .\end{array}$ & & & 12.8 & & & \\
\hline $\mathrm{Lee}(\mathrm{mm})$ & & & & & & & \\
\hline Refreeze (mm) & & & & & & & \\
\hline B.I.L. $(\mathrm{mm})$ & & 0 & 7.9 & & 0 & 4.7 & 0 \\
\hline Film (mm) & 0 & 7.9 & 0 & & 12.8 & 8.1 & 16.4 \\
\hline
\end{tabular}

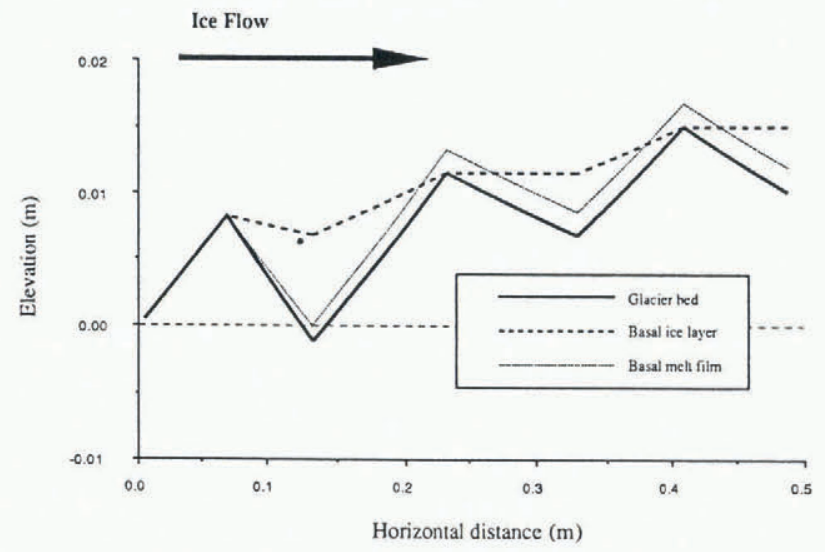

Fig. 3. Representation of the morphologic model components as determined for the first three bedrock hummocks of the long profile reconstructed for Glacier de Tsanfleuron.

Net basal melt-film thickness at bump troughs $(\mathrm{m})-$ this is given by the thickness of the melt film at the crest of the bump less the quantity lost to refreezing at the lee face. This value can be reduced to zero but cannot become negative.

Basal ice-layer (BIL) thickness at bump crests ( $\mathrm{m})$ - the thickness of this layer is given by the effluent basal icelayer thickness from the previous bump less local melting at this bump. If the value is negative, then a basal ice layer does not exist and its thickness is taken to be zero. Basal ice is always assumed to be overlain by isotopically homogeneous glacier ice.

Basal ice-layer (BIL) thickness at bump troughs ( $\mathrm{m})$ - given by the net basal ice-layer thickness at the crest of the bump plus local refreezing.

It is worth noting that the two-dimensional basal ice layer simulated in the current analysis (where the bedrock profiles have been smoothed) responds solely to regelation processes at the bed, whereas in reality such a layer would be neither horizontal nor linear, but moulded to the larger-scale bedrock morphology by the three-dimensional effects of plastic deformation. Similarly, since bedrock morphology transverse to flow is not accounted for, the "thickness" of the net basal meltwater film gives the relative discharge of that film and is not a true measure of its thickness. In addition, no allowance is made in the general model for the basal ice layer leaving the glacier bed and forming cavities in which there is no Weertman regelation, but where there may be net basal melting, freeze-on or detached-ice incorporation (Tison and Lorrain, 1987) depending on the local temperature and cavity configuration. The model has, however, been adapted to include the effects of the system being crossed by a water-filled Nye channel or cavity which is assumed to drain the film water and to melt a proportion of the basal ice forming the cavity ceiling.

The model deals with melting-refreezing events over measured glacier beds on which asymmetric bedrock hummocks are common. However, traditional regelation theory has dealt only with symmetrical bedrock configurations, where mass and energy are neatly balanced over each bump. Whilst this approach permits modelling of the relationships between regelation sliding rates and aggregate bed roughness, it is not regarded as appropriate for the present study. For regelation to occur around asymmetric bedrock hummocks, it is necessary for latent heat to be transferred by conduction through more than one bedrock bump. Since the net bed slope over the profiles is removed by smoothing, the sum of the stoss-face amplitudes approximately equals the sum of the lee-face amplitudes at a scale of some tens of centimetres to metres, and the net quantity of ice melted over such distances therefore approximates the quantity of that formed. Under such conditions, the latent heat required to melt ice at the stoss face of those hummocks where more ice is melted at the stoss face than is refrozen at the lee face is supplied by conduction through the bedrock from those bumps downstream where the opposite situation holds. The alternatives to this scenario either involve basal cavitation at the scale of millimetres or the closure of such voids by plastic deformation of the ice, both of which are unlikely and unsupported by field observations (e.g. Kamb and LaChapelle, 1964). This is not only a computational problem but a theoretical one insofar as, on an actual glacier bed, several bumps may be superimposed over distances on the order of tens of centimetres such that minor zones of refreezing may be located within larger areas of melting and vice versa. A test run of the model has been conducted over symmetric bedrock hummocks in order to assess the effects of using the more realistic, asymmetric bedrock configurations in the analysis. The smoothed bedrock profile for Glacier de Tsanfleuron was adapted so that the net amplitude to wavelength ratio of the surface was preserved, but with individual bedrock bumps which were symmetrical. This was achieved by averaging the stoss-and-lee amplitudes of each hummock and replacing them with their mean value. The horizontal length of the faces was not altered.

The isotopic composition of each model component is dictated by the initial composition of the glacier ice (considered to be homogeneous, with "typical" Alpine ratios of $-12.5 \%$ in $\delta^{18} \mathrm{O}$ and $-90 \%$ in $\delta \mathrm{D}$; Souchez and Jouzel, 1984), fractionation in the lee of each bump and mass-balance considerations. The model is based on the division and conservation of isotopic mass between the basal ice layer and the basal meltwater film from which it refreezes. Thus, local melting contributes to the net basal melt film at the stoss face of each hummock and its magnitude and isotopic composition are correspondingly altered. Similarly, the formation of regelation ice at the lee face depletes the film by the thickness of the refrozen layers, and the isotopic composition of both the new ice formed and the remaining film are determined from the model of Jouzel and Souchez (1982). Thus, at a bump where the thickness of the melt film at the crest is twice the amplitude of the lee face, the isotopic composition of 
the basal ice lamination formed in the lee is given by the cumulative frozen fraction for $K=0.1-0.5$ in the model of Jouzel and Souchez (1982), with an initial liquid composition equal to that of the basal meltwater film at the crest of the bump. The morphology and isotopic composition of the aggregate basal ice layer leaving the bump are then determined, this being composed of the ice frozen locally plus that inherited from upstream hummocks. Occasionally, there may be less meltwater available for refreezing from the film than is required given the amplitude of the lee face and, in such situations, the thickness of ice formed is limited to the quantity in the film.

Isotope distribution in the basal ice is determined from the model of Jouzel and Souchez (1982) as described above. It is assumed that water refreezes first at the crest of the bump and thereafter progressively (and linearly in terms of volume) into the trough. This approximates a heat sink orthogonal to the bedrock surface, and results in a vertical isotopic profile through each refrozen layer similar to that defined for oxygen in Figure 2 and depicted schematically in Figure 4 . Where waters are mixed, they are weighted according to their relative volumes. The isotopic compositions of individual model components computed at each bedrock bump are expressed as $\delta$ values in \%o relative to SMOW and are derived as follows:

Isotopic composition of glacier ice - a constant composition is assumed $\left(\delta^{18} \mathrm{O}=-12.50 \% ; \delta \mathrm{D}=-90.0 \%\right)$.

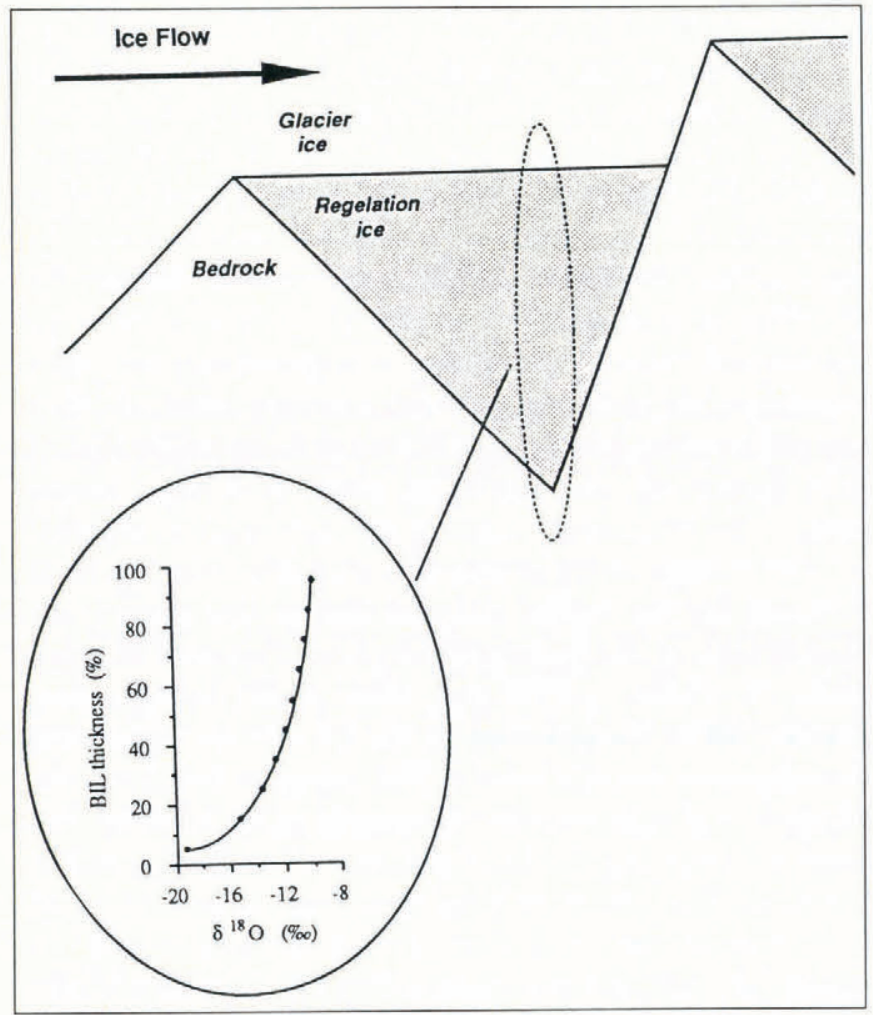

Fig. 4. Schematic representation of the assumed distribution in $\delta^{18} O$ through the regelation ice layer formed by complete refreezing of the available melt in the leeside of a bedrock bump. Note the refrozen layer extends horizontally from the crest of the bump since net basal melting is not considered here.
Basal ice composition at crest of bump - this is the mean composition of the net basal ice layer which survives melting and overlies the crests of certain bumps. This value is determined from the model of Jouzel and Souchez (1982), assuming a single freezing-event isotopic distribution in the influent basal ice layer. For example, where $30 \%$ of the influent basal ice layer is melted, the composition of the surviving basal ice will be given from the model of Jouzel and Souchez as the cumulative composition for $K=0.1-0.7$ using an initial liquid composition given by the mean composition of the net influent basal ice layer. The model thereby accounts for the isotopic distribution in the influent basal ice rather than considering it to be homogeneous. However, influent basal ice is often multi-layered in reality and the assumption of a single freezing-event isotope distribution within it can result in the computation of too heavy an isotopic composition within the remaining layer in certain situations where it is very thin. Where this occurs, it is accounted for by restricting the concentration of $\mathrm{D}$ and ${ }^{18} \mathrm{O}$ in the surviving basal ice to that physically possible according to refreezing theory. This limit is dictated by the composition of the initial liquids from which the individual component layers of the influent basal ice were formed upstream. This effect is not, however, considered to be of great importance since the isotope distribution through multi-layered basal ice closely approximates the distribution through a single refrozen layer with the same mean composition. This becomes apparent below in the analysis of at-a-point vertical isotope profiles through the basal ice.

Net basal melt-film composition at crest of bump - the composition of the net basal meltwater film following melting at each bump is determined by the conservation of isotopic mass. Considerations of mass balance dictate that the aggregate isotopic composition of the surviving basal ice layer and the meltwater film at the crest of each bump equate with a similar quantity of ice or water at the initial isotopic compositions adopted at the beginning of each profile (i.e. $-12.5 \%$ in $\delta^{18} \mathrm{O}$ and $-90 \%$ in $\delta \mathrm{D}$ ). Thus, the total mass of each isotope is held constant in any vertical section along each of the profiles.

Local refrozen ice composition - this is the net composition of the new ice formed in the lee of each bump. The composition of this ice layer is given by Jouzel and Souchez's model according to the proportion of the film refrozen and the composition of the film at the crest of the hummock.

Effluent basal ice-layer composition - this is the net composition of the overall basal ice layer leaving each bump and is equal to the composition of the local refrozen layer plus that of the surviving basal ice layer at the crest of the bump (where one exists), weighted by volume.

Net basal melt composition at bump troughs - this is the composition of the net meltwater film as it leaves each bump. It is given by the composition of the net melt film at the crest of the bump less that lost to refreezing at the lee face, scaled by volume. 

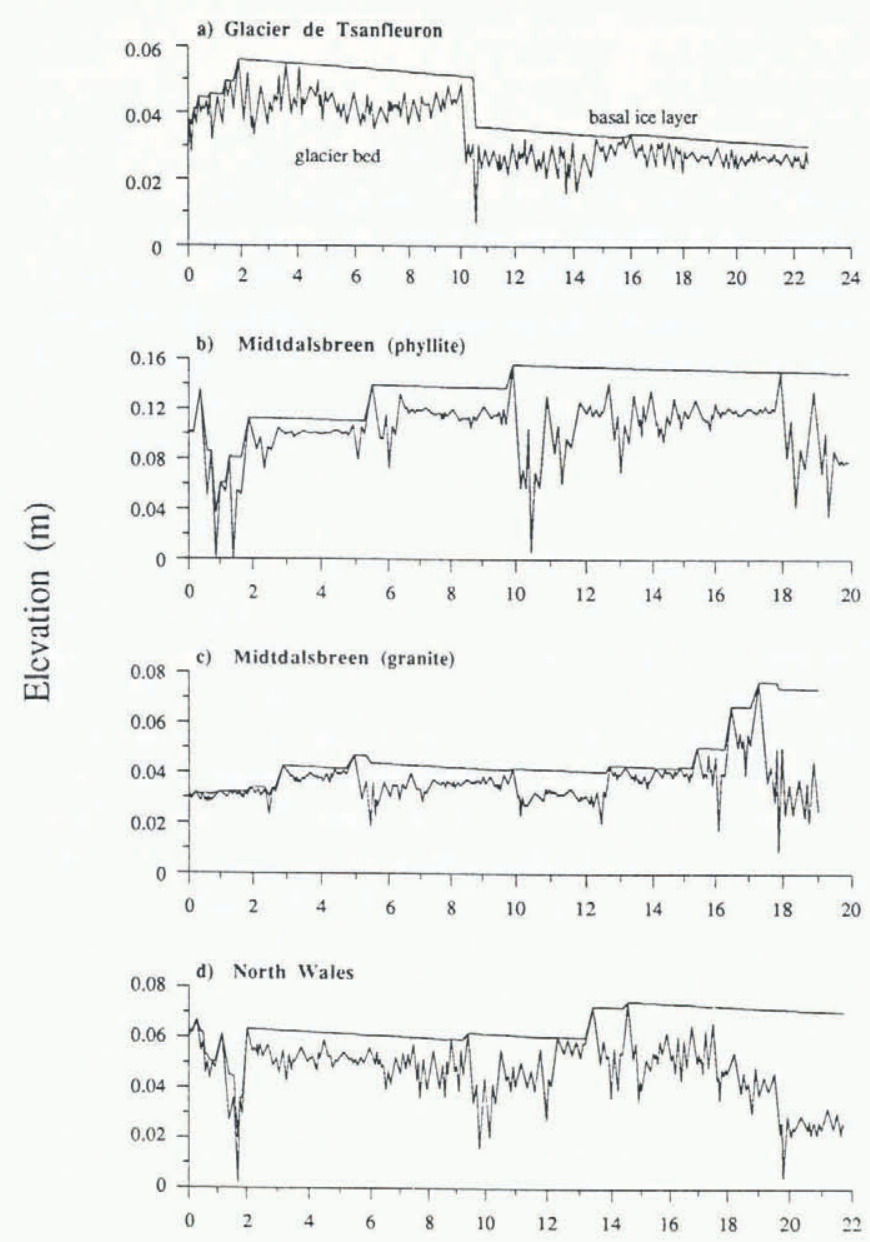

Horizontal distance $(\mathrm{m})$

Fig. 5. The reconstructed glacier bed and basal ice layer over the measured profiles at Tsanfleuron (a), Midtdalsbreen phyllite (b), Midtdalsbreen granite (c) and North Wales ignimbrite (d).

From these data, the basal ice layers (Fig. 5a-d) and net meltwater films (Fig. 6a-d) associated with the four glacier beds can be reconstructed. As expected, the upper surface of the basal ice extends down-glacier from the crest of each bump until it encounters either a stoss face of greater elevation, where it is melted and replaced, or a lee face where there is insufficient water in the basal melt film to allow complete refreezing. The overall basal ice layer thins between these bumps in accordance with the net basal melting term incorporated into the model. Thus, the maximum basal ice-layer thickness over any section (where there is sufficient meltwater available for refreezing) is equal to the maximum relief between the upper surface of the ice layer formed at an upstream crest and a trough downstream of it. If the upper surface of each refrozen lamination is reconstructed, then the internal layering of the net basal ice layer can be determined in vertical section at any location. The initial isotope profile through each layer can be plotted from knowledge of the isotopic composition of the net basal melt film from which each lamination was formed in association with Jouzel and Souchez's model. The overall isotopic sequence through the complete basal ice layer can then be determined as a composite of the constituent laminae, with the melted part of each layer having been removed.
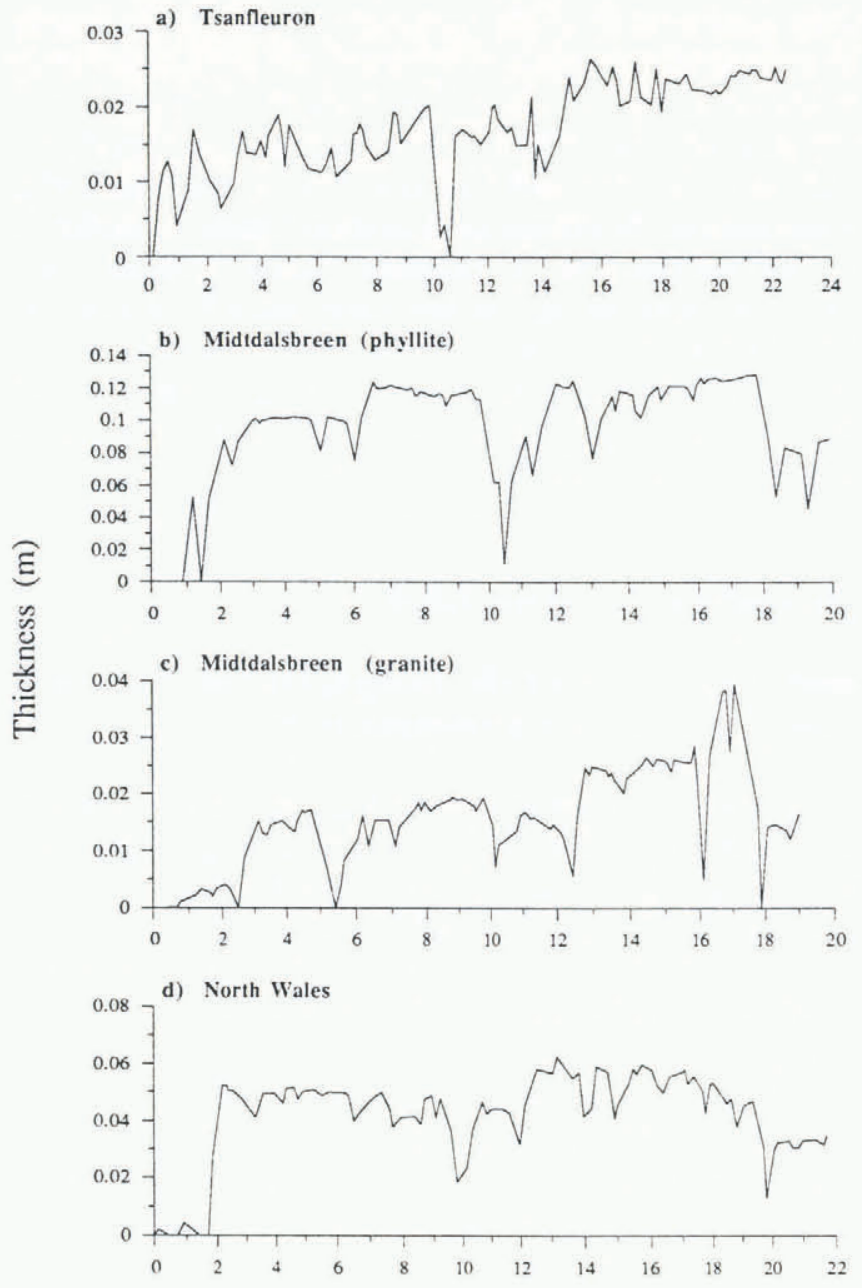

Horizontal distance $(\mathrm{m})$

Fig. 6. The model thickness of the basal meltwater film in each hummock trough for the four profiles: Tsanfleuron (a), Midtdalsbreen phyllite (b), Midtdalsbreen granite (c) and North Wales ignimbrite (d).

One complicating factor is the possible influence of a freezing rate so rapid that individual molecules cannor migrate through a static boundary layer adjacent to the ice at sufficient speed to produce the predicted equilibrium isotopic distribution. This does not so much affect the slope of the co-isotopic plots as the variation of the isotopic ratios with the frozen fraction (" $K$ "), and thereby the distribution of single isotopes through the ice. The fractionation factors used in the present model are averages which were determined empirically over a range of freezing rates (O'Neil, 1968; Arnason, 1969). However, recent work (Souchez and others, 1987; Lehmann and Siegenthaler, 1991) has indicated that the equilibrium fractionation factor is, in effect, replaced by a lower, "apparent" fractionation factor at faster freezing rates. Experimental work carried out by Lehmann and Siegenthaler (1991) indicates that the difference between the two increases linearly with the freezing rate, at least up to speeds of c. $10 \mathrm{~mm} \mathrm{~h}^{-1}$. Souchez and others (1987, 1988b) have simulated the molecular migration responsible for this effect using a box-diffusion model and were able, under certain circumstances, to predict the isotope profile through adfrozen ice.

Given that the rate of basal ice formation by 
regelation is roughly the same as the basal sliding speed, here assumed to be $20 \mathrm{~m} \mathrm{a}^{-1}\left(2.3 \mathrm{~mm} \mathrm{~h}^{-1}\right)$, it is likely that the present system is only affected by "fast-freezing" effects to a minimal extent. In order to assess this effect, we have run the model for the Tsanfleuron bed using three different hydrogen-fractionation factors. In addition to the equilibrium fractionation factor (1.0208), the apparent fractionation factors used relate to a realistic freezing rate of $2 \mathrm{~mm} \mathrm{~h}^{-1}(1.0201)$ and an excessive one of $48 \mathrm{~mm} \mathrm{~h}^{-1}$ (1.0116). For consistency, all were derived from Arnason's experiments, with the latter two publlished in Souchez and others (1987).

\section{RESULTS AND DISCUSSION}

\section{Bed roughness and the morphology of the regel- ation ice layer and meltwater film}

Thickness variations of the basal ice and meltwater film over each long profile are given in Table 2. The thickness of the regelation ice layer is on the order of millimetres to centimetres, and the basal meltwater film can be completely frozen at a number of locations along the profiles. Occasionally, the basal ice layer is melted completely at the crests of bumps. For all profiles, the mean thickness in leeside troughs ranges from 11 to $42 \mathrm{~mm}$ and the maximum thickness from 29 to $149 \mathrm{~mm}$. The Midtdalsbreen phyllite bed is significantly rougher than the others (Table 1), with a mean amplitude to wavelength ratio (measured at each bump as the mean height of the stoss-and-lee faces divided by the bump length) of 0.140 , while the mean roughness for the rest of the beds is 0.034 . This is reflected in the generally greater thickness of the basal ice layer generated over this profile.
The mean and maximum thicknesses of the basal ice layer formed over the phyllite bed are 42 and $149 \mathrm{~mm}$, respectively, whereas they are 12 and $65 \mathrm{~mm}$ over granite at the same glacier. Since these two profiles are located within $250 \mathrm{~m}$ of each other, it is likely that the differences in roughness and concomitant basal ice-layer thickness are therefore due to lithological and/or structural controls. In general, it is probable that harder rock types are more resistant to the abrasive smoothing of high-frequency roughness features, while structural controls exert an important influence on the generation of roughness by fracture. Foliae in the rock tend to result in small-scale roughness and joints in periodic steps. In this light, it is significant that the granite at Midtdalsbreen is relatively isotropic while the phyllite is strongly foliated and jointed. The model prediction of an undeformed, basal regelation-ice layer up to $15 \mathrm{~cm}$ thick over the phyllite should therefore be taken as realistic, although this was exceptional and was preserved for only $12 \mathrm{~cm}$ over the entire reconstructed profile of almost $20 \mathrm{~m}$.

In general, the magnitude of the net basal meltwater film increases along each profile in accordance with the melting term incorporated into the model. However, significant departures from this trend result from the asymmetric nature of the bedrock hummocks with, for example, the film thinning to zero even at a distance of $18 \mathrm{~m}$ along the Midtdalsbreen (granite) profile. The greater roughness of the phyllite bed than the others also results in the production of a thicker meltwater "film" here, reaching $16 \mathrm{~cm}$ at bump crests and $13 \mathrm{~cm}$ in the troughs, while the maximum thickness of the film over the granite bed is c. $6.5 \mathrm{~cm}$. These values correspond only indirectly to meltwater volumes and do not reflect the actual film thickness. In reality, meltwater flows laterally around bedrock hummocks and the film thickness would

Table 2. Summary of basal ice thickness and melt quantities generated over the four bedrock profiles

\begin{tabular}{|c|c|c|c|c|c|}
\hline \multirow[t]{2}{*}{ Glacier } & & Film (crest) & Film (trough) & BIL (crest) & BIL (trough) \\
\hline & & $\mathrm{m}$ & $\mathrm{m}$ & $\mathrm{m}$ & $\mathrm{m}$ \\
\hline \multirow[t]{3}{*}{ Tsanfleuron } & Mean & 0.0227 & 0.0171 & 0.0053 & 0.0108 \\
\hline & Minimum & 0.0079 & 0.0000 & 0.0000 & 0.0023 \\
\hline & Maximum & 0.0299 & 0.0264 & 0.0202 & 0.0287 \\
\hline \multirow{3}{*}{$\begin{array}{l}\text { Midtdalsbreen } \\
\text { (phyllite) }\end{array}$} & Mean & 0.1141 & 0.0985 & 0.0263 & 0.0419 \\
\hline & Minimum & 0.0014 & 0.0000 & 0.0000 & 0.0014 \\
\hline & Maximum & 0.1600 & 0.1282 & 0.0858 & 0.1487 \\
\hline \multirow{3}{*}{$\begin{array}{l}\text { Midtdalsbreen } \\
\text { (granite) }\end{array}$} & Mean & 0.0205 & 0.0154 & 0.0064 & 0.0115 \\
\hline & Minimum & 0.0009 & 0.0000 & 0.0000 & 0.0009 \\
\hline & Maximum & 0.0649 & 0.0395 & 0.0387 & 0.0649 \\
\hline \multirow[t]{3}{*}{ North Wales } & Mean & 0.0511 & 0.0424 & 0.0141 & 0.0228 \\
\hline & Minimum & 0.0027 & 0.0000 & 0.0000 & 0.0007 \\
\hline & Maximum & 0.0799 & 0.0625 & 0.0464 & 0.0669 \\
\hline
\end{tabular}


be greatly reduced both by this redistribution and by it flowing at a higher velocity than the sliding speed of the glacier. Water may also drain away from the regelationfilm system at the glacier bed, perhaps by concentrating to form channels or by flowing into pre-existing channels where these cross the system. However, the quantitative extent of this thinning cannot be determined with any certainty in the absence of data relating to lateral bedrock morphology at the sites, and this has not therefore been attempted in the present study.

\section{Down-glacier evolution in single isotopes}

With an initial glacier-ice isotopic composition of $-12.5 \%$ in $\delta^{18} \mathrm{O}$ and $-90 \%$ in $\delta \mathrm{D}$ the downstream isotopic changes, given for $\delta^{18} \mathrm{O}$ in Figure $7 \mathrm{a}-\mathrm{d}$, are significant both in a theoretical context and in the light of data obtained in the field. Hydrogen isotope ratios mirror oxygen closely for all model components and the coisotopic plots are discussed below. A logical result of the preservation of several partial layers of regelation ice is that it is the first frozen fraction that remains in each case.
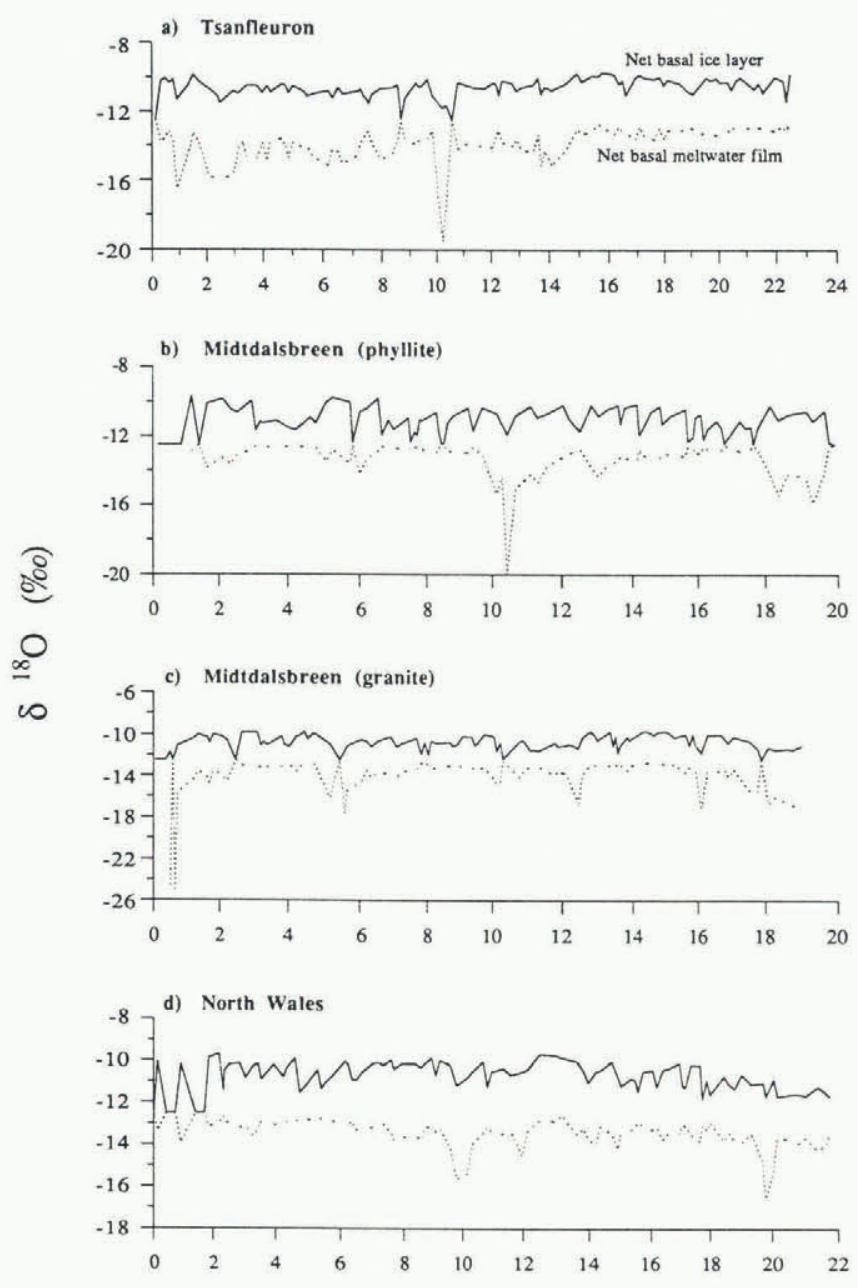

Horizontal distance $(\mathrm{m})$

Fig. 7. The composition in $\delta^{18} O$ of the effluent basal ice layer and the net basal meltwater film over the analysed long profiles: Tsanfleuron (a), Midtdalsbreen phyllite (b), Midtdalsbreen granite (c) and North Wales ignimbrite (d).
The basal ice layer as a whole is therefore less depleted in heavy isotopes than the film. However, the requirement for conservation of mass renders the system self-regulating since the film is itself the source of subsequently formed basal ice. Thus, as the net basal melt becomes depleted or enriched in heavy isotopes so, in general, does the basal ice formed from it, although the ice is always heavier than the film. One consequence of this is that the film composition can never become more enriched in heavy isotopes than the initial input values $\left(-12.50 \%\right.$ in $\delta^{18} \mathrm{O}$, $-90.0 \%$ in $\delta \mathrm{D})$. Similarly, the mean composition of the net basal ice layer cannot become lighter than those initial values.

Summary data for the isotopic composition of the ice and waters in the model are given in Table 3 . The most depleted model component is the net basal meltwater film leaving each bump ("film trough") as it represents the meltwater remaining at the lee face after the local refrozen layer has formed. In addition, this meltwater film is already depleted in heavy isotopes relative to the basal ice since it is incremented by melting of the lowermost, and therefore lightest, fraction of the influent ice layer at each stoss face. The mean isotopic value of the net basal melt film leaving each hummock ranges from $-13.25 \%$ in $\delta^{18} \mathrm{O}(-94.5 \%$ in $\delta \mathrm{D})$ over the phyllite profile at Midtdalsbreen to $-14.00 \%$ ( $-99.3 \%$ o $)$ over the granite bed at the same glacier. Concomitantly, the basal ice layer at the crest of bedrock hummocks is the least depleted in heavy isotopes, ranging from a mean value of $-10.51 \%$ o $(-77.5 \%$ ) over the Tsanfleuron bed to $-11.10 \%$ o $(-81.3 \%$ o $)$ over the phyllite bed at Midtdalsbreen. These mean values mask significant local variations in the isotopic composition of the model components. Wherever the meltwater film thins locally its composition becomes anomalously light, reflecting the incorporation of the heavy isotopes into the refrozen ice. Such excursions in the film composition occur at about $10.1 \mathrm{~m}$ over the Tsanfleuron profile, $10.4 \mathrm{~m}$ over the phyllite profile and at $0.5 \mathrm{~m}$ over the granite profile (Fig. 7). In each case, the film composition falls to below c. $-18 \%$ in $\delta^{18} \mathrm{O}$ and $-130 \%$ in $\delta \mathrm{D}$, while the new basal ice formed immediately following these events is also depleted in the heavy isotopes, but to a lesser extent due to the input from local melting.

The isotopic partitioning between the basal ice and the meltwater film predicted by the model results in a glacier-wide fractionation process. Taking all four modelled profiles, the mean $\delta^{18} \mathrm{O}$ value for the effluent basal ice layer from each bump is $-10.84 \%$, whereas the composition of the net basal melt is $-13.65 \%$. While this latter value may be more depleted in $\delta^{18} \mathrm{O}$ than that which might be expected in the field (where the basal film may mix intermittently with other waters), the difference between this value and that of the glacier-ice input to the model is $1.15 \%$. This value is in close accordance with field measurements such as those conducted by Theakstone (1988) at Austre Okstindbreen, Norway, where the net base flow was reported to be depleted in $\delta^{18} \mathrm{O}$ by at least $1.26 \%$ relative to the possible source waters. Significantly, it is the base-flow component of meltwater discharge which would be most affected by large-scale fractionation during regelation, since it is a continuous process which occurs in the absence of surface melting. 
Table 3. Isotopic composition of the basal ice and meltwater components generated by the model

\begin{tabular}{|c|c|c|c|c|c|c|c|c|c|c|c|}
\hline \multirow[t]{3}{*}{ Glacier } & & \multirow{2}{*}{\multicolumn{2}{|c|}{$\begin{array}{c}B I L \text { (crest) } \\
\%\end{array}$}} & \multirow{2}{*}{\multicolumn{2}{|c|}{$\begin{array}{c}\text { Film (crest) } \\
\%\end{array}$}} & \multirow{2}{*}{\multicolumn{2}{|c|}{$\begin{array}{c}\text { Local refrozen } \\
\% \\
\%\end{array}$}} & \multirow{2}{*}{\multicolumn{2}{|c|}{$\begin{array}{c}\text { BIL (trough) } \\
\%\end{array}$}} & \multirow{2}{*}{\multicolumn{2}{|c|}{$\begin{array}{c}\text { Film (trough) } \\
\%\end{array}$}} \\
\hline & & & & & & & & & & & \\
\hline & & $\delta^{18} \mathrm{O}$ & $\delta \mathrm{D}$ & $\delta^{18} \mathrm{O}$ & $\delta \mathrm{D}$ & $\delta^{18} \mathrm{O}$ & $\delta \mathrm{D}$ & $\delta^{18} \mathrm{O}$ & $\delta \mathrm{D}$ & $\delta^{18} \mathrm{O}$ & $\delta \mathrm{D}$ \\
\hline \multirow[t]{3}{*}{ Tsanfleuron } & Mean & -10.51 & -77.5 & -12.95 & -92.8 & -10.47 & -77.0 & -10.61 & -78.1 & -13.87 & -98.6 \\
\hline & Minimum & -12.50 & -90.0 & -15.36 & -108.0 & -15.35 & -107.9 & -12.50 & -90.0 & -19.50 & -133.8 \\
\hline & Maximum & -9.69 & -72.1 & -12.50 & -90.0 & -9.69 & -72.1 & -9.69 & -72.1 & -12.53 & -90.2 \\
\hline \multirow{3}{*}{$\begin{array}{l}\text { Midtdalsbreen } \\
\text { (phyllite) }\end{array}$} & Mean & -11.10 & -81.3 & -12.78 & -91.6 & -10.21 & -75.2 & -11.15 & -81.8 & -13.25 & -94.5 \\
\hline & Minimum & -12.50 & -90.0 & -14.59 & -103.2 & -12.70 & -90.9 & -12.50 & -90.0 & -19.99 & -135.4 \\
\hline & Maximum & -9.69 & -72.1 & -12.50 & -90.0 & -9.69 & -72.1 & -9.69 & -72.1 & -12.51 & -90.1 \\
\hline \multirow{3}{*}{$\begin{array}{l}\text { Midtdalsbreen } \\
\text { (granite) }\end{array}$} & Mean & -10.66 & -78.4 & -12.97 & -92.6 & -10.59 & -77.4 & -10.83 & -79.3 & -14.00 & -99.3 \\
\hline & Minimum & -12.50 & -90.0 & -15.07 & -106.3 & -14.72 & -98.0 & -12.50 & -90.0 & -24.93 & $3-167.5$ \\
\hline & Maximum & -9.69 & -72.1 & -12.50 & -90.0 & -9.69 & -72.1 & -9.69 & -72.1 & -12.62 & -90.8 \\
\hline \multirow[t]{3}{*}{ North Wales } & Mean & -10.74 & -79.0 & -12.92 & -92.3 & -10.39 & -76.1 & -10.75 & -78.8 & -13.46 & -95.9 \\
\hline & Minimum & -12.50 & -90.0 & -14.89 & -102.8 & -14.89 & -98.5 & -12.50 & -90.0 & -16.53 & $3-115.3$ \\
\hline & Maximum & -9.69 & -72.1 & -12.50 & -90.0 & -9.69 & -72.1 & -9.69 & -72.1 & -12.59 & -90.5 \\
\hline
\end{tabular}

The internal compositions in $\delta^{18} \mathrm{O}$ of vertical sections through the basal ice at its thickest point in each profile are plotted in Figure 8a-d and the results are summarized in Table 4. Again, the distribution in $\delta^{18} \mathrm{O}$ is closely mirrored by that in $\delta \mathrm{D}$. As expected, the isotope distribution in each section is broadly similar to that which would have existed in the ice layer had it formed from only one refreezing event. Ice is isotopically heaviest at the top of the cross-section and lightest at the base.
This is due to the fact that individual laminae frozen into the basal ice layer upstream generally represent surviving first-frozen fractions while the youngest ice layer which underlies them at the base of each profile is complete. There are, however, many small-scale departures from this pattern within the profiles, the detail of which is determined by upstream bed configuration. The internal laminae in any vertical basal ice section reflect the number and elevation of bedrock crests upstream of the

Table 4. Summary data in $\delta^{18} O$ for the vertical sections plotted in Figure $8 a-d$

\begin{tabular}{|c|c|c|c|c|c|c|c|c|c|}
\hline \multirow[t]{3}{*}{ Glacier } & \multirow{3}{*}{$\begin{array}{c}\text { Net BIL } \\
\text { thickness } \\
\qquad \mathrm{mm}\end{array}$} & \multirow[t]{3}{*}{$\begin{array}{l}\text { Number of } \\
\text { layers }\end{array}$} & \multicolumn{3}{|c|}{ Individual layer thickness } & \multicolumn{2}{|c|}{$\begin{array}{l}\text { Initial liquid } \\
\qquad \delta^{18} O\end{array}$} & \multicolumn{2}{|c|}{$B I L \delta^{18} O$} \\
\hline & & & \multicolumn{3}{|c|}{$\mathrm{mm}$} & \multicolumn{2}{|c|}{$\%$} & \multicolumn{2}{|c|}{$\%$} \\
\hline & & & Mean & Min. & Max. & Min. & Max. & Min. & Max. \\
\hline Tsanfleuron & 28.7 & 5 & 5.7 & 0.4 & 17.7 & -15.35 & -12.50 & c. -24 & -9.3 \\
\hline $\begin{array}{l}\text { Midtdalsbreen } \\
\text { (phyllite) }\end{array}$ & 148.7 & 2 & 72.5 & 47.1 & 97.9 & -13.45 & -12.50 & c. -22 & -9.3 \\
\hline $\begin{array}{l}\text { Midtdalsbreen } \\
\text { (granite) }\end{array}$ & 64.9 & 2 & 32.5 & 26.7 & 38.2 & -13.76 & -12.50 & c. -24 & -9.3 \\
\hline North Wales & 66.9 & 6 & 11.2 & 2.1 & 22.1 & -13.46 & -12.50 & c. -22 & -9.3 \\
\hline
\end{tabular}


Hubbard and Sharp: Multiple freezing events and evolution of basal layer

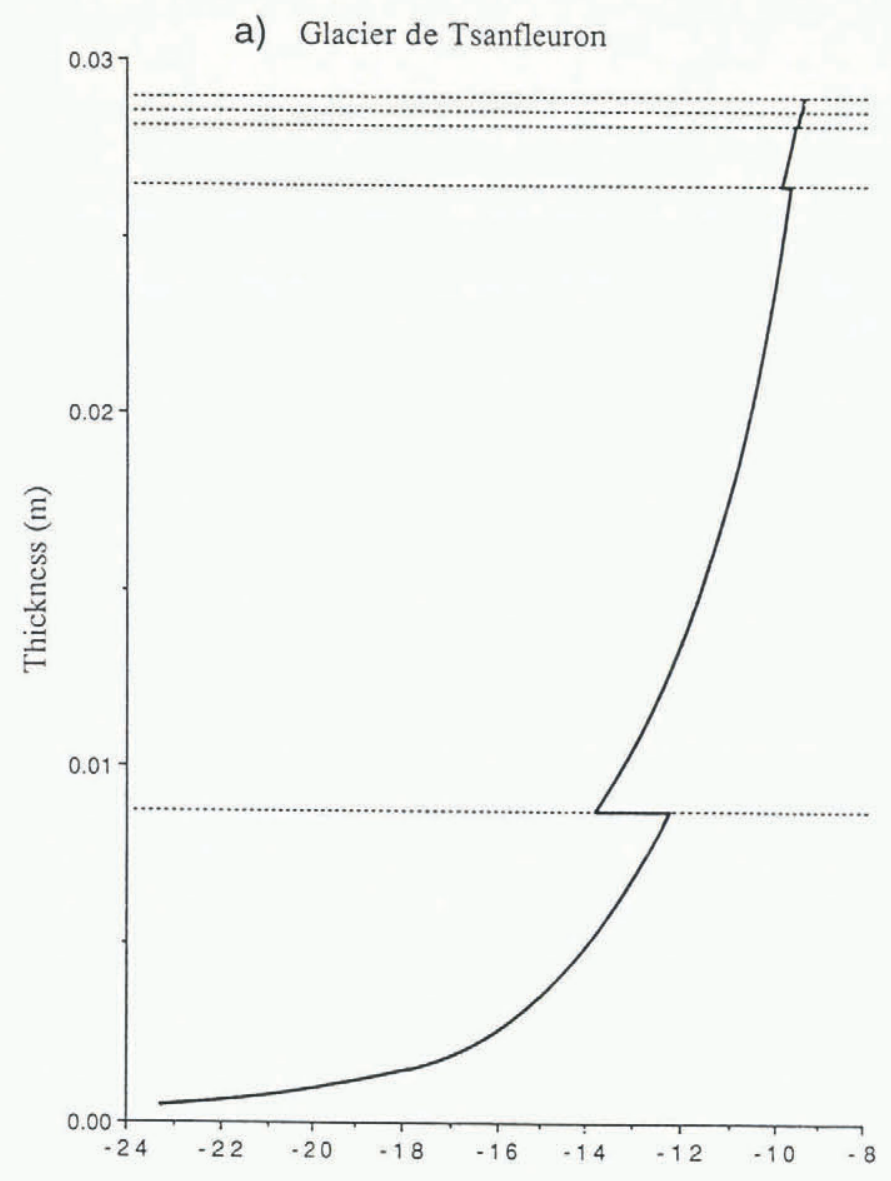

$\delta^{18} 0$

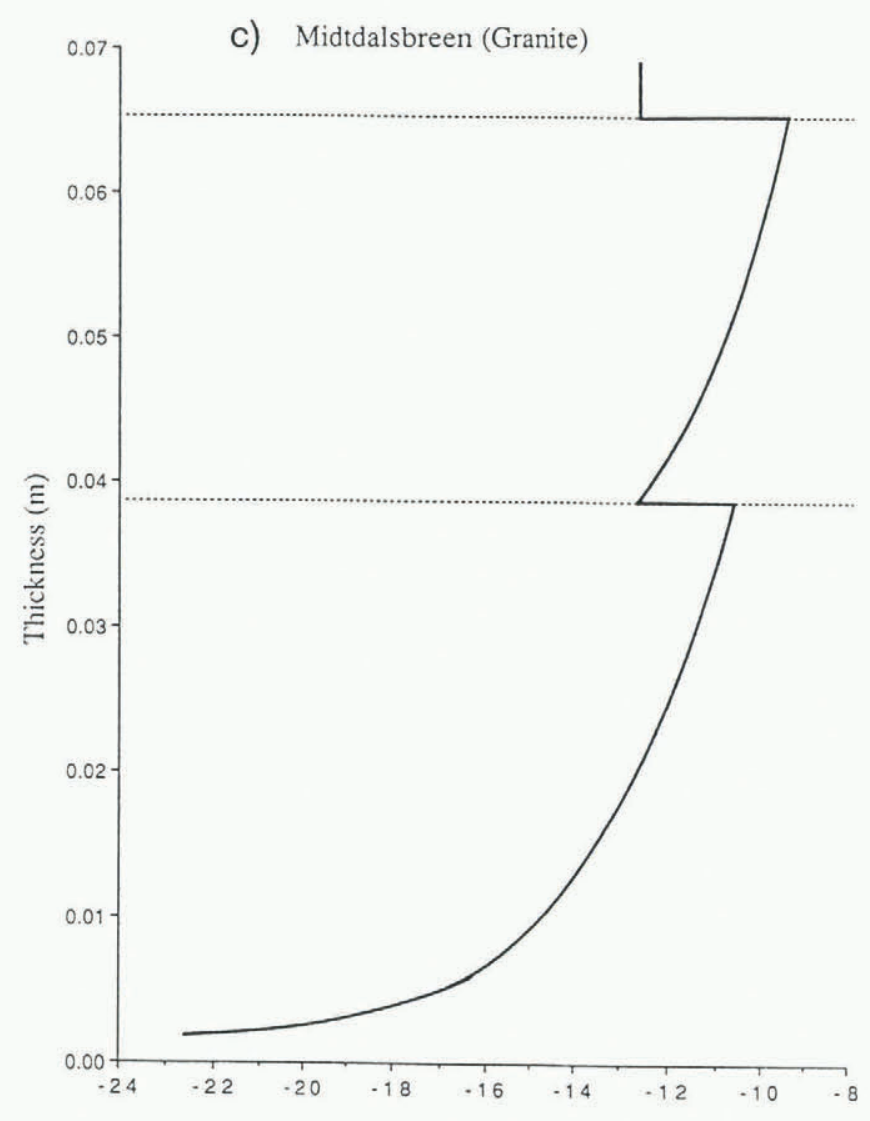

$\delta^{18} 0$

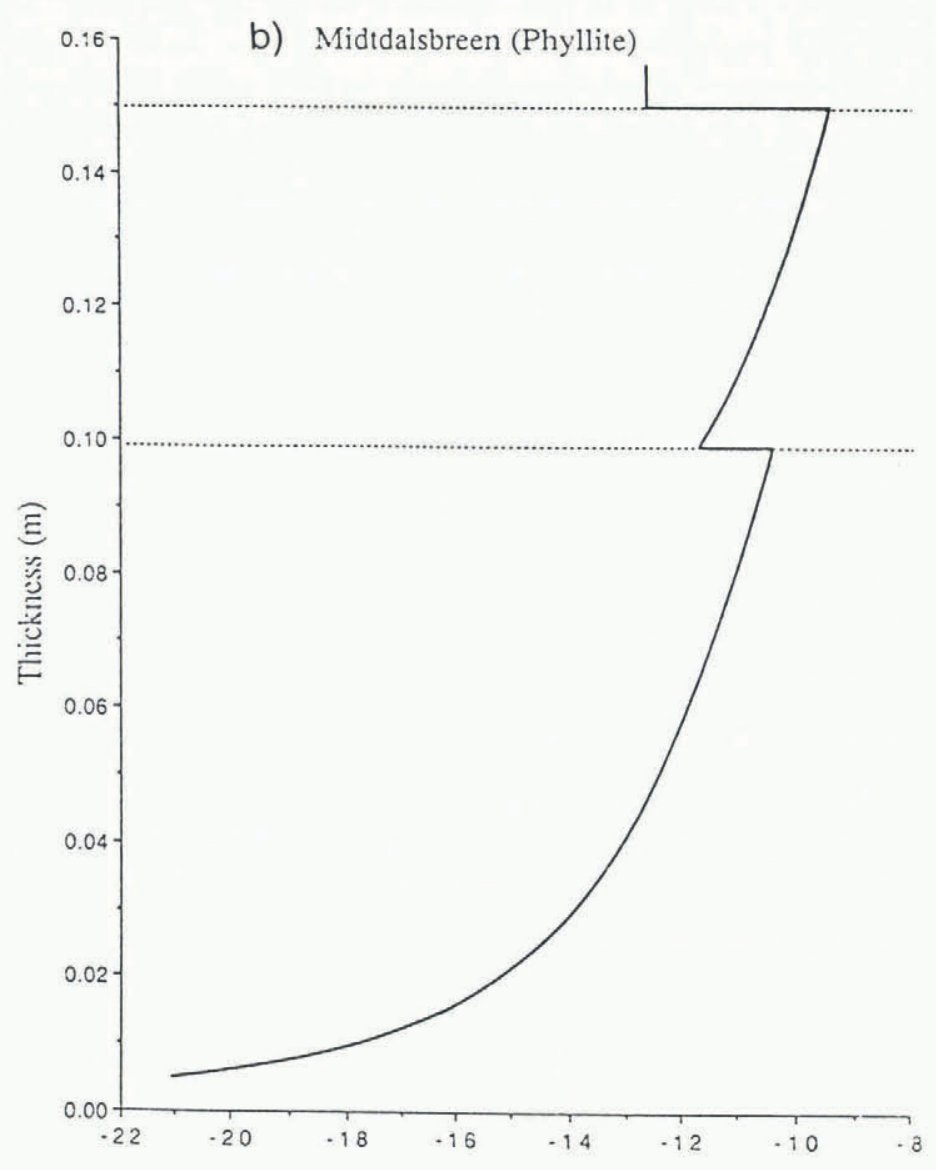

$\delta^{18} 0$

d) North Wales

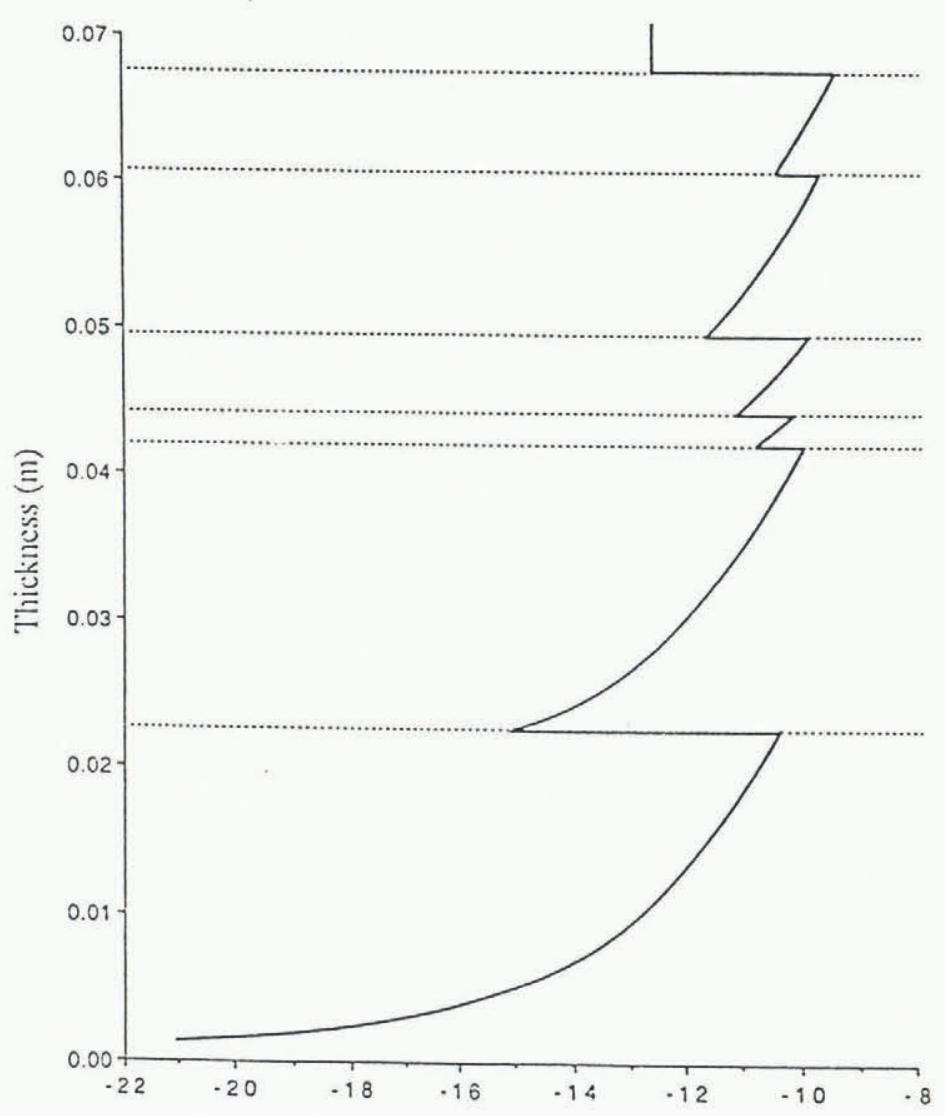

$\delta^{18} 0$

Fig. 8. Vertical plots in $\delta^{18} O$ through the thickest basal ice cross-section formed over each bedrock profile: Tsanfleuron (a), Midtdalsbreen phyllite (b), Midtdalsbreen granite (c) and North Wales ignimbrite (d). 
Table 5. $\delta D$ values for the Glacier de Tsanfleuron profile comparing the effects of two lower, apparent fractionation factors with that used in the model. The apparent fractionation factors are 1.0201 and 1.0116, which correspond to freezing rates of $2 \mathrm{~mm} \mathrm{~h}^{-1}$ and $48 \mathrm{~mm} \mathrm{~h}^{-1}$, respectively (from Souchez and others, 1987)

\begin{tabular}{|c|c|c|c|c|c|c|c|c|c|c|c|c|c|c|c|}
\hline & \multicolumn{3}{|c|}{ BIL (crest) } & \multicolumn{3}{|c|}{ Film (crest) } & \multicolumn{3}{|c|}{$\begin{array}{l}\text { Local } \\
\text { refrozen }\end{array}$} & \multicolumn{3}{|c|}{ BIL (trough) } & \multicolumn{3}{|c|}{ Film (trough) } \\
\hline & & $\delta \mathrm{D} \%$ & & & $\delta \mathrm{D} \%$ & & & $\delta \mathrm{D} \%$ & & & $\delta \mathrm{D} \%$ & & & $\delta \mathrm{D} \%$ & \\
\hline $\begin{array}{l}\text { Fractionation } \\
\text { factor }(\alpha)\end{array}$ & 1.0208 & 81.0201 & 1.0116 & 1.0208 & 31.0201 & 1.0116 & 1.0208 & 1.0201 & 1.0116 & 1.0208 & 1.0201 & 1.0116 & 1.0208 & 1.020 & 11.0116 \\
\hline $\begin{array}{l}\text { Freezing } \\
\text { rate } \\
\qquad\left(\mathrm{mm} \mathrm{h}^{-1}\right)\end{array}$ & “0”" & 2.0 & 48.0 & “0” & 2.0 & 48.0 & "0" & 2.0 & 48.0 & “0” & 2.0 & 48.0 & “"0” & 2.0 & 48.0 \\
\hline
\end{tabular}

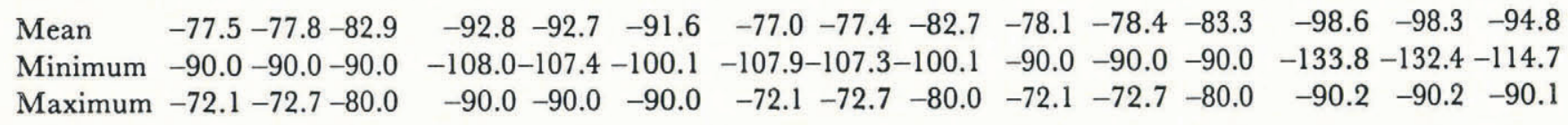

point concerned which protrude above all crests which follow them, allowing for a general thinning due to net basal melting. The two Midtdalsbreen ice layers are composed of only two laminae, while the Tsanfleuron vertical profile includes five and that reconstructed for North Wales six. These plots demonstrate the sensitivity of isotopic analysis to the size of the sample recovered and its location within the profile. $\delta^{18} \mathrm{O}$ values within the vertical profiles range between -9.3 and c. $-24 \%$ for each reconstruction. The former value is fixed by the composition of the meltwater film from which the uppermost layer in each vertical profile formed. Preservation of mass within the system dictates that the composition of the water at such a location (the crest of a hummock where all of the influent basal ice layer is melted) is $-12.5 \%$ in $\delta^{18} \mathrm{O}$ and $-90 \%$ in $\delta \mathrm{D}$. However, initial liquid composition (given by the composition of the net basal melt film at the crests of the bumps from which the individual layers originate) does vary and, for example, ranges from -12.50 to $-15.35 \%$ in $\delta^{18} \mathrm{O}$ through the vertical cross-section reproduced for the Tsanfleuron bed (Table 4). In general, therefore, multiple refreezing events and partial layer preservation result in a wider range of isotopic values than would be produced by a single adfreezing event of similar magnitude. In addition, local reversals in the vertical isotopic profile are probable and should be expected in reality where samples are collected at a fine enough scale.

\section{Freezing-rate effects}

The qualitative effect of introducing a lower fractionation factor into the model is to reduce the variation in isotopic composition of the model components. Thus, isotopic excursions from the initial values $(-12.5 \% ;-90 \%$ ) occur as before, but they are reduced in magnitude such that the lightest meltwater is not so light and the heaviest basal ice is not so heavy. This is borne out by the averaged $\delta \mathrm{D}$ concentrations of the principal model components calculated using the different fractionation factors (Table 5). As expected, the differences between the model results using the equilibrium fractionation factor (1.0208) and that corresponding to a more realistic freezing speed of $2 \mathrm{~mm} \mathrm{~h}^{-1}$ (1.0201) are very small, and all values are within $1 \%$ of each other. Whilst these differences are more significant when a fractionation factor corresponding to a freezing rate of $48 \mathrm{~mm} \mathrm{~h}^{-1}$ (1.0116) is used, they still do not dramatically alter the model's results. Moreover, a freezing rate of $48 \mathrm{~mm} \mathrm{~h}^{-1}$ is much faster than that assumed in the model $(2.3 \mathrm{~mm}$ $\mathrm{h}^{-1}$ ), which is, in turn, significantly faster than the actual sliding rate measured by the authors in a marginal cavity at Glacier de Tsanfleuron (mean annual speed c. $\left.0.6 \mathrm{~mm} \mathrm{~h}^{-1}, 1989-90\right)$. Sharp and others (1989b) applied Nye's (1969) sliding theory without cavitation to the spectral representation of the profile at Glacier de Tsanfleuron and, assuming a basal shear stress of $100 \mathrm{kPa}$, obtained a predicted basal sliding velocity of $0.02 \mathrm{~mm} \mathrm{~h}^{-1}$. We do not therefore believe, given the range of these measured and predicted sliding speeds, that nonequilibrium freezing effects alter the results of the current model to a significant extent.

\section{The influence of bedrock-hummock asymmetry}

The replacement of the asymmetric bedrock configuration at Glacier de Tsanfleuron with that composed of symmetric hummocks has several predictable effects on the model results. These are presented in Figure 9. The amplitude of the larger face of each bump is reduced halfway to the amplitude of the smaller face, and the maximum basal ice-layer thickness is correspondingly reduced from $28.7 \mathrm{~mm}$ over the initial asymmetric profile to $16.7 \mathrm{~mm}$ over the symmetric one. Similarly, the minimum basal ice-layer thickness is correspondingly increased. With the exception of the meltwater resulting 

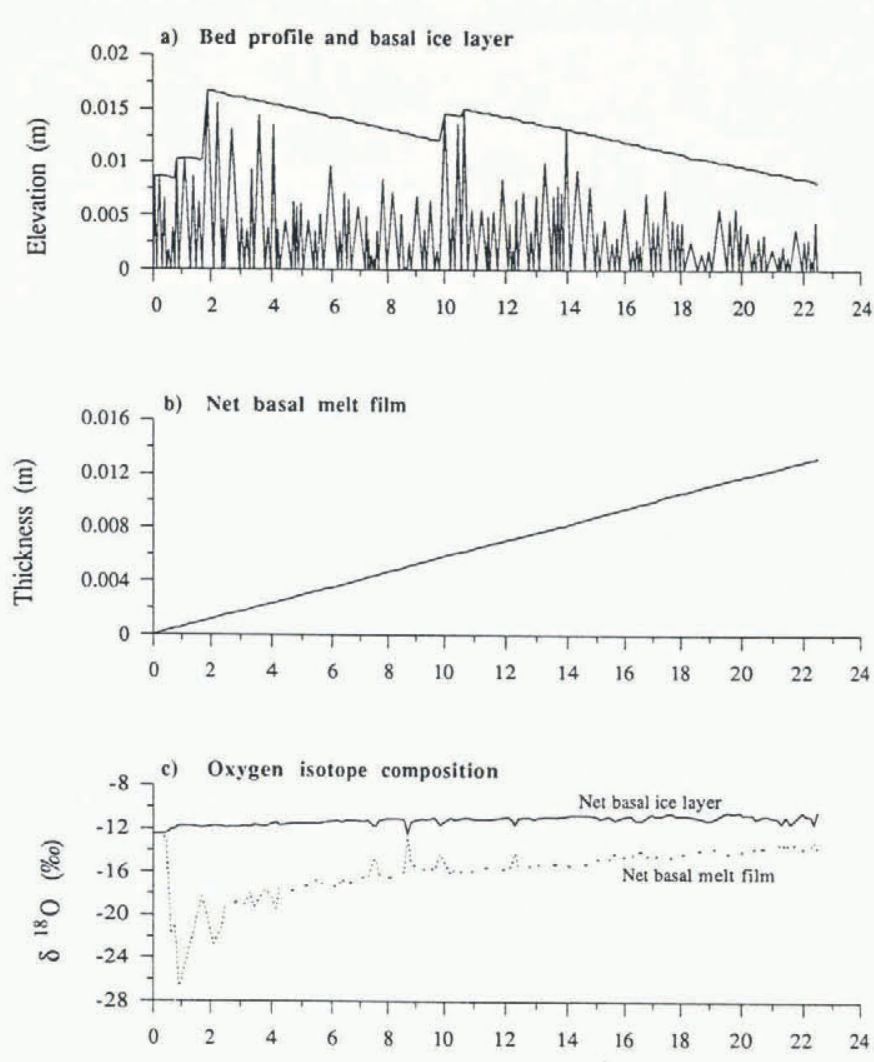

Horizontal distance $(\mathrm{m})$

Fig. 9. The thickness of the basal ice layer (a) and meltwater film (b) and their isotopic composition (c) over the Glacier de Tsanfleuron profile with symmetrical bedrock hummocks.

from the net basal melting term in the model, all of the influent ice melted at the stoss face of each bump is refrozen in the lee. There is therefore no net gain or loss of meltwater over individual bumps, and the quantity of melt increased linearly over the profile in accordance with the net basal melting term adopted in the model. In the absence of a similar trend in the basal ice thickness, conservation of mass dictates that the isotopic composition of the film progresses steadily towards the aggregate value of the inputs $\left(-12.5 \%\right.$ in $\left.\delta^{18} \mathrm{O}\right)$. Whilst large initial excursions in the film composition are possible, these are soon dampened out as its volume increases. Consequently, as ice progresses along the profile, the individual refrozen layers generally represent a smaller fraction of the water reservoir available for freezing. The net basal ice composition therefore also tends towards a steady-state value representing $K=0.1$ of the composition of the melt film, which itself tends towards $-12.5 \%$ in $\delta^{18} \mathrm{O}$.

These results do not provide support for the simplifying assumption of adopting symmetrical bedrock hummocks. Under this assumption, both the basal melt film and the basal ice tend rapidly to steady-state values which clearly do not correspond to samples collected in the field. The range of basal ice compositions generated by the model over symmetrical hummocks is from -10.38 to $-12.50 \%$ in $\delta^{18} \mathrm{O}$, whereas samples recovered from this glacier and reported in Sharp and others (1990) extend from -9.35 to $-15.80 \%$ in $\delta^{18} \mathrm{O}$. We therefore conclude that, where possible, realistic bedrock profiles should be utilized in the analysis of regelation phenomena, and that the incorporation of asymmetric and variable hummock configurations should represent a priority to theoretical treatment of the problem.

\section{Co-isotopic plots}

It is evident from Tables 3 and 4 that there is a strong relationship between the composition of the net basal ice layer in $\delta^{18} \mathrm{O}$ and $\delta \mathrm{D}$. The correlation is, however, not perfect and a minor degree of scatter has been introduced into the system by the variation in the initial liquid composition. Taking the data for the profile at Glacier de Tsanfleuron, the mean, minimum and maximum isotopic ratios for the net basal meltwater film at bump crests are $-12.95,-15.36$ and $-12.50 \%$ in $\delta^{18} \mathrm{O}$ and $-92.8,-108.0$ and $-90.0 \%$ in $\delta \mathrm{D}$. If these values are substituted as initial liquids into Equation (4), then the resulting theoretical freezing slopes for the individual basal ice layers generated at Glacier de Tsanfleuron are 6.37, 6.28 and 6.39 , respectively. Thus, samples recovered over these layers would each be expected, from theory, to fall on a co-isotopic slope between that of 6.28 and 6.39. In this case, the degree of scatter of samples is very small and the actual plot in $\delta^{18} \mathrm{O}$ and $\delta \mathrm{D}$ of the net effluent basal ice layers generated by the model for the Tsanfleuron bed (Fig. 10) results in a statistical correlation $\left(r^{2}\right)$ of 0.998 around a slope of 6.36 . Thus, whilst a degree of scatter in the co-isotopic plots of individual samples does result from fluctuations in initial liquid composition, the effect is minor over the range of initial liquids predicted by the present model. However, this scatter would be expected to be greater in reality, where a wider range of initial liquids would result from inhomogeneities in the isotopic composition of the glacier ice and where the model assumptions of closed system hydrology might break down.

\section{Heavy-isotope enrichment in the basal zone - the influence of drainage into water-filled cavities}

Sharp and others (1990) have studied the geochemistry of calcite precipitates formed as a consequence of solute rejection and concentration in association with the regelation process at Glacier de Tsanfleuron (Hallet and others, 1978). They argued on isotopic grounds that

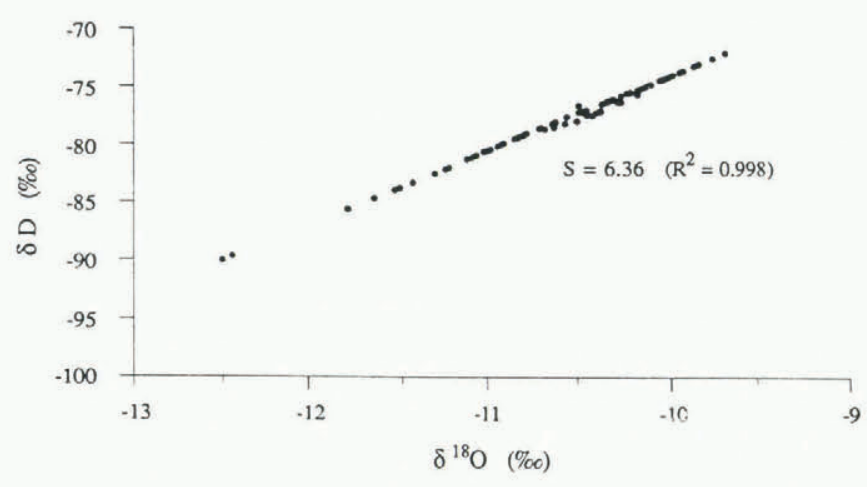

Fig. 10. Co-isotopic plot of the composition of the net effluent basal ice layer at Glacier de Tsanfleuron. 
calcite precipitation occurs when the basal melt layer is dominated by ${ }^{18} \mathrm{O}$-rich local, basally derived water and is not diluted with ${ }^{16} \mathrm{O}$-rich surface-derived meltwater. However, $\delta^{18} \mathrm{O}$ values measured for certain precipitate samples require a source water with a composition as enriched in $\delta^{18} \mathrm{O}$ as $-8.00 \%$, while the heaviest basal ice and meltwater samples obtained by the authors are -9.35 and $-9.25 \%$, respectively. Significantly, the initial refreezing of meltwater of $-8.00 \%$ in $\delta^{18} \mathrm{O}$ would result in the formation of regelation ice as heavy as $-5.00 \%$, well in excess both of any basal ice sample yet obtained in the field and of the composition of any basal ice as predicted in the current model.

As noted above, the basal meltwater film in the current model cannot become more enriched in heavy isotopes than the initial composition of the glacier ice; i.e. $-12.5 \%$ in $\delta^{18} \mathrm{O}$ and $-90 \%$ in $\delta \mathrm{D}$. This, in turn, restricts the composition of the basal ice formed from this film to a maximum value slightly heavier than $-9.69 \%$ in $\delta^{18} \mathrm{O}$ and $-72.1 \%$ in $\delta \mathrm{D}$. In order to generate basal ice heavier than this, either water heavier than the assumed initial composition must be introduced to the system or relatively light water must be lost from the basal melt film. It is probable that water would be lost from the regelation system where the film is crossed by a network of water-filled linked cavities. If consideration is given to both the length of the reconstructed glacier beds (each c. $20 \mathrm{~m}$ ) and the results of morphological mapping of the proglacial bedrock at Glacier de Tsanfleuron (Sharp and others, 1989b), it seems probable that the regelation meltwater film would be crossed by discrete drainage pathways or cavities at a number of points along each of the profiles analysed. Although little is known about such interactions at the glacier bed, the current model has been modified in order to incorporate a number of logical effects. In this case, the most pronounced bedrock trough in the Tsanfleuron profile is taken to be filled with water flowing at a pressure lower than that in the surrounding film. This is assumed to have the following effects:

No ice is frozen at the lee face of the hummock forming the upstream side of the cavity.

All film water entering the cavity from upstream is removed from the model.

The lower half of the basal ice entering the cavity from upstream is melted at the ice/water interface and the meltwater removed from the system along with the influent film water.

No meltwater is generated at the stoss face of the hummock which forms the down-glacier side of the cavity.

The effect is similar to beginning the profile again, but with an initial basal ice layer in place which is heavier than the overlying glacier ice. The basal ice layer here is $0.0101 \mathrm{~m}$ thick with a net isotopic composition of $-9.69 \%$ o in $\delta^{18} \mathrm{O}$. The mass-balance parameters of the model are correspondingly adjusted at this point and the downglacier evolution of the basal ice layer and meltwater film and their isotopic compositions are given in Figure 11a-c.
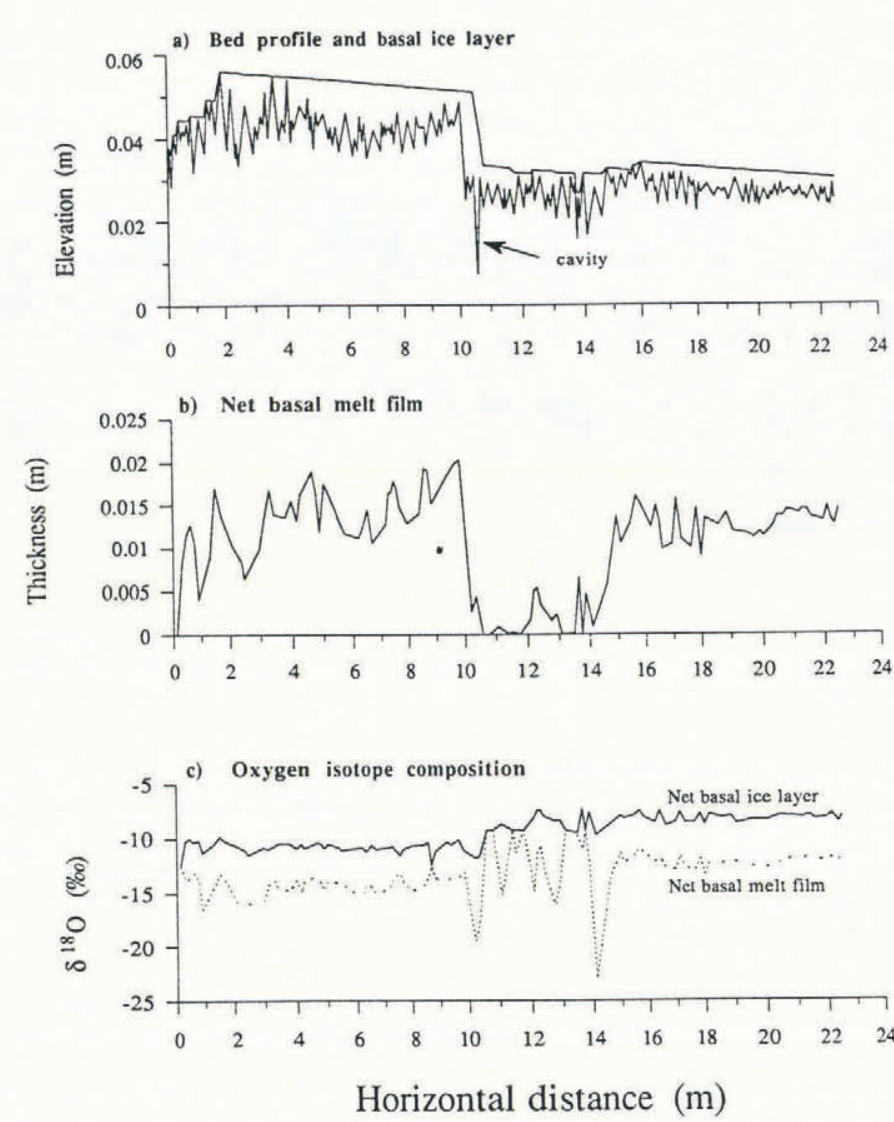

Fig. 11. The thickness of the basal ice layer (a) and meltwater film (b) and their isotopic composition (c) at Glacier de Tsanfleuron incorporating disruption of the system by a water-filled Nye-type channel flowing in the major trough formed at $10.6 \mathrm{~m}$.

The principal morphological effects result from the removal of the film at this point which reduces the supply of meltwater available for excess refreezing downstream. This is reflected in the general thinning of the basal ice layer down-glacier of the interruption, where the meltwater film thins to zero in the lee of several hummocks. The principal isotopic effect is to raise the heavy-isotope content of the system such that the mean and maximum $\delta$ composition of all the model components increase (Table 6). Significantly, following the interruption the composition in $\delta^{18} \mathrm{O}$ of the net basal ice layer rises to a maximum value of $-7.33 \%$ in the bump troughs and $-6.61 \%$ over the bump crests. Similarly, the meltwater film is comparably enriched in ${ }^{18} \mathrm{O}$ along the remainder of the profile, rising to a maximum composition of $-9.49 \%$. Thus, it does appear in the light of this simulation that basal ice may approach a composition as enriched as $-5 \%$ in $\delta^{18} \mathrm{O}$ in the regelation system at the glacier bed at Tsanfleuron. Indeed, such an effect would be expected in reality where it might be assumed that such hydrological interactions are repeated many times as ice flows over its bed.

The dependence of the isotopic composition of ice on the size of the sample recovered is critical here. While the heaviest net basal meltwater film generated along the profile is $-9.49 \%$ in $\delta^{18} \mathrm{O}$, ice formed from the freezing of this water will be as enriched in $\delta^{18} \mathrm{O}$ as $-6.68 \%$. This ice, however, would represent the first frozen fraction in the model of Jouzel and Souchez and, with a mean lee-face 
Hubbard and Sharp: Multiple freezing events and evolution of basal layer

Table 6. $\delta^{18} O$ values for the Glacier de Tsanfleuron profile with disruption of the regelation system by a Nye-type

channel. Where they are different, isotopic compositions for the normal model are given in brackets

\begin{tabular}{|c|c|c|c|c|c|}
\hline $\begin{array}{l}\text { Glacier de } \\
\text { Tsanfleuron } \\
\text { with cavity }\end{array}$ & BIL (crest) & Fïlm (crest) & $\begin{array}{l}\text { Local } \\
\text { refrozen }\end{array}$ & BIL (trough) & Film (trough) \\
\hline
\end{tabular}

$\begin{array}{lccccr}\text { Mean } & -8.82(-10.51) & -12.05(-12.95) & -9.78(-10.47) & -9.50(-10.61) & -13.41(-13.87) \\ \text { Minimum } & -12.50 & -15.36 & -13.31 & -12.50 & -22.96(-19.50) \\ \text { Maximum } & -6.61(-9.69) & -9.49(-12.50) & -7.44(-9.69) & -7.33(-9.69) & -9.76(-12.53)\end{array}$

amplitude for the Tsanfleuron bed of $5.7 \mathrm{~mm}$, the entire regelation layer concerned is likely to be less than $1 \mathrm{~mm}$ thick. Thus, any sample recovered using an ice screw with an internal bore of tens of millimetres (or, indeed, even an order of magnitude less than this) will not therefore register such ${ }^{18} \mathrm{O}$-enriched ice, even when ice of that composition exists and has been included in the sample.

\section{CONCLUSIONS}

The determination of roughness profiles for real glacier beds and the simulation of the evolution of basal ice as it slips by regelation over these beds has led to a number of important conclusions. It is evident that bed roughness at the scale relevant to Weertman regelation is extremely variable in the field and that much of this variability is due to innate lithological or structural differences in the substiate. Basal ice layers generated by regelation over such beds are of the order of millimetres to centimetres thick, often non-existent and exceptionally in excess of $10 \mathrm{~cm}$. This is in broad agreement with both theoretical considerations and field observations. Such layers are not internally homogeneous but are composed of a sequence of laminae, each morphologically and compositionally distinct. One cannot assume an average representative individual refrozen layer thickness for sampling purposes. Indeed, individual regelation layers may not even be identifiable in the field. Whilst the upper limits of refrozen layers are often demarcated by debris laminae frozen into the ice (Fig. 1), there is no a priori reason to believe that this holds in all cases or at all times. Nor can it be assumed that individual layers are either wholly or partially preserved - only detailed isotopic analysis at a scale of millimetres can reveal such information. In reality, morphological complexity may also derive from zones of net basal melting or adfreezing in accordance with influent warm or cold air or the operation of processes such as Robin's (1976) heat pump. Whilst it is extremely difficult to incorporate quantitatively the effects of such influences, they may have to be accounted for in terms of further variability in the analysis of the isotopic composition of basal ice sequences beneath otherwise temperate glaciers.

The isotopic composition of regelation ice layers changes and evolves downstream in a similar and related manner to the internal morphology. Down-glacier evolution of both the basal ice layer and the net basal meltwater film results in a large-scale fractionation effect with the former being consistently less depleted in heavy isotopes than the latter. Such a temporally and spatially extensive fractionation process may go some way to explaining field observations of meltwater base flow which is isotopically lighter than possible bulk input sources (Theakstone, 1988). The magnitude of this fractionation is of the order of $3 \%$ in $\delta^{18} \mathrm{O}$ over the profiles reconstructed for the present analysis and in the absence of dilution by external waters. Where disruption of the basal regelation-meltwater-film system by drainage into a network of linked cavities is modelled, it appears possible for the heavy-isotope composition of both the basal ice and the meltwater film to rise to new steadystate values. Heavy-isotope enrichment could also arise from the incorporation of glacier ice of variable composition into the model. In this case, the effect could be either to enrich the system in heavy isotopes or to diminish it, depending on the composition of the newly incorporated ice relative to the existing aggregate composition of the basal ice and meltwater.

The plotting of cross-sectional isotopic profiles reveals that there is much more internal variability in laminated ice sequences than is evident from sampling at a scale of tens of millimetres. Such variability, in association with down-glacier evolution in the model components, may carry important consequences for the range in isotopic ratios obtained from ice samples recovered at different scales. In general, the smaller the scale of sampling the wider the possible range of results. Such internal inhomogeneity may also be significant to co-isotopic analysis of the basal ice layer. Beneath a glacier, the proportion of initial refrozen layers preserved as individual laminae is unknown and while some may be preserved whole, thereby conserving bulk mass and plotting on the precipitation slope, others will represent partial fractions of the parent layers and will plot on the freezing slope. This would not represent a problem if samples were recovered from within individual internal layers, but, as we have seen, samples recovered by the traditional method may be composed of several such laminae. The contribution of this effect to co-isotopic scatter in the current model is difficult to assess as the net basal ice layer at any location is composed of a series of 
partial layers, not only of different thicknesses, but also with each representing a different degree of freezing from the initial reservoir.

Similarly, the initial liquids from which regelation layers are formed are not constant and a small degree of scatter in individual samples around the theoretical freezing slope can be expected from this effect. While the slope of co-isotopic plots, defined in Equation (4), is relatively insensitive to initial liquid variability of the order predicted by the present analysis (c. $3 \%$ in $\delta^{18} \mathrm{O}$ and $20 \%$ in $\delta \mathrm{D}$ ), the effect is responsible for minor departures from the aggregate freezing slope.

Both the morphology and isotopic composition of regelation ice layers can be extremely variable solely as a result of multiple refreezing events at the beds of temperate glaciers. In reality such complexity is further compounded by discrete zones of net melting or freezing, plastic deformation and tectonic thickening of the basal ice layer. In addition, it is possible that continuous clearice layers may represent more than one refreezing event in situations where there is an absence of comminuted debris available at the interface for incorporation. Whilst each of these complicating factors is beyond the scope of the present model, they may have to be accounted for in the analyis of regelation ice layers as they exist in the field.

\section{ACKNOWLEDGEMENTS}

The authors are grateful to Dr J. -L. Tison, Dr R. Lorrain and Dr J. Jouzel for critical comments on both the model and an earlier draft of the text. B.H. is supported by a U.K. Natural Environment Research Council studentship.

\section{REFERENCES}

Arnason, B. 1969. Equilibrium constant for the fractionation of deuterium between ice and water. F. Phys. Chem., 73(10), 3491-3494.

Craig, H., L. I. Gordon and Y. Horibe. 1963. Isotopic exchange effects in the evaporation of water. Science, 133, 1833-1834.

Goodman, D.J., G.C.P. King, D.H. M. Millar and G. de Q. Robin. 1979. Pressure-melting effects in basal ice of temperate glaciers: laboratory studies and field observations under Glacier d'Argentière. F. Glaciol., 23(89), 259-272.

Gordon, J. E., W. G. Darling, W.B. Whalley and A. F. Gellatly. $1988 . \delta \mathrm{D}-\delta^{18} \mathrm{O}$ relationships and the thermal history of the basal ice near the margins of two glaciers in Lyngen, north Norway. 7. Glaciol., 34(118), 265268.

Hallet, B. 1976. Deposits formed by subglacial precipitation of a $\mathrm{CaCO}_{3}$. Bull. Geol. Soc. Am., 87, 1004-1015.

Hallet, B., R. Lorrain and R. Souchez. 1978. The composition of basal ice from a glacier sliding over limestones. Bull. Geol Soc. Am., 89(2), 314-320.

Hooke, R. LeB. and N. R. Iverson. 1985. Experimental study of ice flow around a bump: comparison with theory. Geogr. Ann., 67A(3-4), 187-197.

Jouzel, J. and R. A. Souchez. 1982. Melting-refreezing at the glacier sole and the isotopic composition of the ice. f. Glaciol., 28(98), 35-42.

Kamb, B. 1970. Sliding motion of glaciers: theory and observation. Rev. Geophys. Space Phys., 8(4), 673-728.

Kamb, B. and E. LaChapelle. 1964. Direct observation of the mechanism of glacier sliding over bedrock. $\mathcal{J}$. Glaciol., 5(38), 159-172.

Knight, P.G. 1987. Observations at the edge of the Greenland ice sheet: boundary condition implications for modellers. International Association of Hydrological Sciences Publication 170 (Symposium at Vancouver 1987 - The Physical Basis of Ice Sheet Modelling), 359-366.

Koerner, R. M. 1989. Ice core evidence for extensive melting of the Greenland ice sheet in the last interglacial. Science, 244(4907), 964-968.

Lehmann, M. and U. Siegenthaler. 1991. Equilibrium oxygen- and hydrogen-isotope fractionation between ice and water. 7. Glaciol., 37(125), 23-26.

Nye, J.F. 1969. A calculation on the sliding of ice over a wavy surface using a Newtonian viscous approximation. Proc. R. Soc. London, Ser. A, 311, 445-467.

Nye, J.F. 1970. Glacier sliding without cavitation in a linear viscous approximation. Proc. R. Soc. London, Ser. A, 315(1522), 381-403.

O'Neil, J.R. 1968. Hydrogen and oxygen isotope fractionation between ice and water. 7. Phys. Chem., 72(10), 3683-3684.

Paterson, W.S.B. 1981. The physics of glaciers. Second edition. Oxford, etc., Pergamon Press.

Robin, G. de Q. 1976. Is the basal ice of a temperate glacier at the pressure melting point? $\mathcal{F}$. Glaciol., 16(74), 183-196.

Sharp, M., J. A. Dowdeswell and J. C. Gemmell. 1989a. Reconstructing past glacier dynamics and erosion from glacial geomorphic evidence: Snowdon, North Wales. 7. Quat. Sci., 4(2), 115-130.

Sharp, M., J. C. Gemmell and J.-L. Tison. 1989b. Stucture and stability of the former subglacial drainage system of the Glacier de Tsanfleuron, Switzerland. Earth Surface Processes and Landforms, 14(2), 119-134.

Sharp, M., J. -L. Tison and G. Fierens. 1990. Geochemistry of subglacial calcites: implications for the hydrology of the basal water film. Arct. Alp. Res., 22(2), 141-152.

Souchez, R. A. 1987. Correspondence. Isotopic fractionation at the base of polar and sub-polar glaciers. $\mathcal{J}$. Glaciol., 33(114), 246.

Souchez, R.A. and J.M. de Groote. 1985. $\delta \mathrm{D}-\delta^{18} \mathrm{O}$ relationships in ice formed by subglacial freezing: palaeoclimatic implications. F. Glaciol., 31(109), 229232.

Souchez, R. A. and J. Jouzel. 1984. On the isotopic composition in $\delta \mathrm{D}$ and $\delta^{18} \mathrm{O}$ of water and ice during freezing. 7. Glaciol., 30(106), 369-372.

Souchez, R., J.-L. Tison and J. Jouzel. 1987. Freezing rate determination by the isotopic composition of the ice. Geophys. Res. Lett., 14(6), 599-602.

Souchez, R., R. Lorrain, J.-L. Tison and J. Jouzel. 1988a. Co-isotopic signature of two mechanisms of basal-ice formation in Arctic outlet glaciers. Ann. Glaciol., 10, 163-166.

Souchez, R., J. -L. Tison and J. Jouzel. 1988b. Deuterium 
concentration and growth rate of Antarctic first-year sea ice. Geophys. Res. Lett., 15(12), 1385-1388.

Sugden, D. E. and 6 others. 1987a. Evidence for two zones of debris entrainment beneath the Greenland ice sheet. Nature, 328(6127), 238-241.

Sugden, D. E., C.M. Clapperton, J.C. Gemmell and P. G. Knight. 1987b. Stable isotopes and debris in basal glacier ice, South Georgia, Southern Ocean. J. Glaciol., 33(115), 324-329.

Theakstone, W. H. 1988. Temporal variations of isotopic composition of glacier-river water during summer: observations at Austre Okstindbreen, Okstindan, Norway. F. Glaciol., 34(118), 309-317.

Tison, J. -L. and R. D. Lorrain. 1987. A mechanism of basal ice-layer formation involving major ice-fabric changes. F. Glaciol., 33(113), 47-50.
Walder, J.S. 1986. Hydraulics of subglacial cavities. F. Glaciol., 32(112), 439-445.

Weertman, J. 1957. On the sliding of glaciers. F. Glaciol., 3(21), 33-38.

Weertman, J. 1964. The theory of glacier sliding. $\mathcal{J}$. Glaciol., 5(39), 287-303.

Willis, I. C., M.J. Sharp and K.S. Richards. 1990. Configuration of the drainage system of Midtdalsbreen, Norway, as indicated by dye-tracing experiments. F. Glaciol., 36(122), 89-101.

The accuracy of references in the text and in this list is the responsibility of the authors, to whom queries should be addressed. 